\title{
حرية الأقليات غير المسلمة في العالم الإسلامي
}

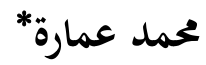

تمهيد:

في تفسير الإمام النسفي (710ه/1310م) مدارك التنزيل وحقائق التأويل، تعليل لحكمة التشريع في

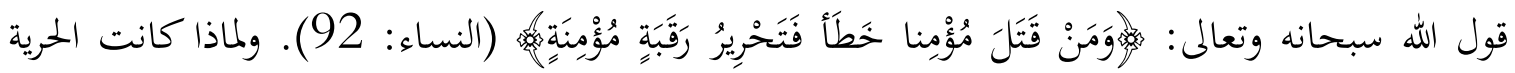
والتحرير هي المقابل للقتل والإماتة، يقول "النسفي" فيه: "إنه -أي القاتل- لما أخرج نفسا مؤمنة من جملة الأحياء، لزمه أن يدخل نفسا مثلها في جملة الأحرار، لأن إطلاقها من قيد الرق كإحيائها، من قِبَل أن الرقيق

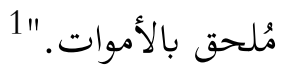

وهذا الفكر الذي يساوي بين الحرية والتحرير وبين الحياة والأحياء، لأن الرق والعبودية -في نظرهموت وموات، والذي عرفته الحضارة الإسلامية قبل معرفة الغرب للنهضة والحرية والتنوير، ورغم تراث الإغريق الذي يكرس الرق والعبودية، باعتبارهما "الطبيعة والضرورة" المحققة لحياة "الأحرار"! هذا الفكر الذي سطره "النسفي" لم يكن بجرد اجتهاد فكري، أو مض إبداع بشري، وإنما كان التفسير والتطبيق للوحي القرآني، الذي جعل جماع رسالة الرسول الخاتم محمد بن عبد الله صلى الله عليه وسلم، تحطيم الأغلال التي تقيد

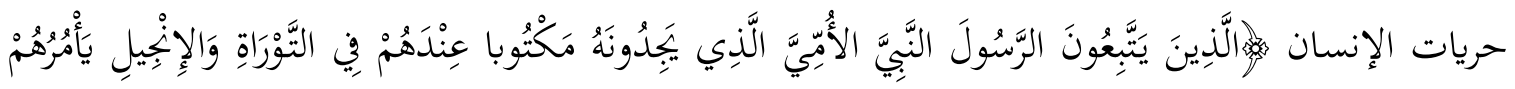

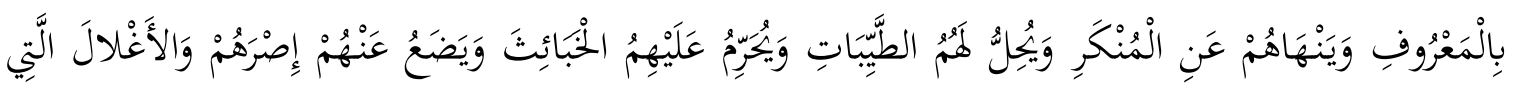

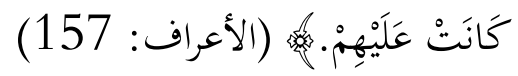

ولأن الإسلام دين ودولة، وبجتمع وأمة، واجتماع وحضارة ونظام، فلقد تحول قرآنه إلى ممارسات وتطبيقات وتاريخ ومعاملات، ولم يقف عند حدود الآيات التي تتلى في الصلوات، ولا النظريات

$$
\text { | * دكتوراه في الفلسفة، مؤلف وعقق ومفكر إسامي من جمهورية مصر العربية. }
$$

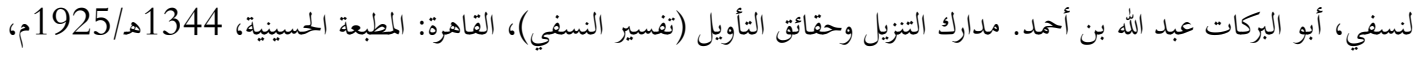

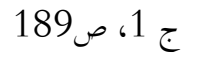


والفلسفات؛ لقد حرر الضمير الإنساني من الإكراه الديني، وحررت فتوحات دولته شعوب الشرق من الطغيان الذي قهرها وقهر حضاراتما ودياناتا عشرة قرون، ثم ترك جماهير هذه الشعوب وما يدينون.

ولقد ظل التنوع الديني - في الديانات السماوية والوضعية- وكذلك التنوع الفلسفي والمذهبي والفكري، في الحضارة الإسلامية والتاريخ الإسلامي شاهد صدق على هذه "الثورة الإصلاحية" التي أنجها الإسلام في ميدان الحرية والتحرير لضمير الإنسان؛ بينما ضاقت حضارات أخرى حتى بالاختلاف المذهبي داخل الدين الواحد! فقامت فيها الحروب الدينية التي امتدت قرونا، والتي أبيد فيها 40\% من شعوب وسط أوربا، وذلك فضلا عن المآسي الدموية لمحاكم التفتيش!

ولقد شهد بكل ذلك المنصفون من غير أبناء الإسلام، بل وكتبوا فيه أكثر مما كتب أبناء الإسلام! ومع كل ذلك، رأينا ونرى في -واقعنا المعاصر - مشاريع الهيمنة الغربية تفتري على الإسلام أنه يضيق بالحرية، وخاصة حريات الأقليات غير المسلمة التي تعيش في ديار الإسلام، وذلك لاتخاذ هذه الافتراءات ذرائع لاختراق الأمن الوطني والقومي والحضاري للشعوب الإسلامية من خلال ثغرات هذه الأقليات؛ إذم يتحدثون عن حرية الأقليات بينما يحرمون الأمة كلها من حريتها الفطرية في تقرير المصير!

لذلك كانت هذه الدراسة -عن "الأقليات غير المسلمة في العالم الإسلامي"- ضرورية لفضح هذه الأكاذيب، بتقديم حقائق الموقف الإسلامي -النظري والتطبيقي- من قضية الحرية التي قرها الإسلام وطبقتها حضارته وصانتها أمته لمذه الأقليات. إنما درس في الحرية التي جعلها الإسلام فطرة معادلة للحياة، والتي طبقها المسلمون عبر تاريخ الإسلام.

\section{أولا :مفهوم الأقلية}

مصطلح "الأقلية"، في استخداماتنا الثقافية والاجتماعية الحديثة والمعاصرة، مصطلح وافد من المفاهيم الغربية التي وفدت إلى واقعنا الثقافي والاجتماعي منذ الاحتكاك بين حضارتنا الإسلامية والحضارة الغربية في 
العصر الحديث. لذلك، فهو مصطلح محمل بالمعاني والظلال "العنصرية -الإثنية- والعرقية" التي ارتبط بها في الثقافة الغربية، عندما استخدم للتعبير عن "الأفراد الذين يعتبرون أنفسهم، أو يعتبرهم الآخرون، مشتركين في بعض السمات والخصائص التي تميزهم عن التجمعات الأخرى في بجتمع يستطيعون في إطاره تطوير سلوكهم

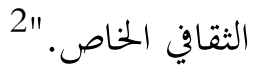

فالأقلية -"الإثنية"- بهذا المفهوم الغربي، ليست مجرد أقلية عددية، ولا هي بالأقلية السياسية، وإنما هي أقلية لها "هوية ثقافية" مختلفة عن الهوية الثقافية لأغلبية المجتمع الذي تعيش فيه، وهويتها الثقافية هذه عادة ما تتطور في ابتاه متميز أو مختلف عن الهوية الغالبة على أغلبية المجتمع الذي تعيش فيه. ولذلك، ولهذا السبب، نفهم رفض أقباط مصر -وهم أقلية عددية- ورفضنا معهم، إطلاق مصطلح "الأقلية"، بهذا المفهوم الغربي عليهم.. فَهُويَُُّهمْ الثقافية والقومية والحضارية -بل وحتى الأصول العرقية- هي ذاتما هوية الأغلبية المسلمة وأصولها. ومن هنا كان الصدق وكانت الإصابة لقول "الأنبا موسى" -أسقف الشباب بالكنيسة الأرثوذكسية المصرية "نخ كأقباط، لا نشعر أننا أقلية، لأنه ليس بينا وبين إخواننا المسلمين فرق عرقي "إثنى"، لأننا مصريون، يجرى فينا دم واحد من أيام الفراعنة- ومن جهة الهوية العربية، فنحن نحيا العربية لأنها هويتنا الثقافية. والثقافة الإسلامية هي السائدة الآن. وأي قبطي يحمل في الكثير من حديثه تعبيرات إسلامية، يتحدث بها ببساطة ودون شعور بأها دخيلة بل هي جزء من مكوناته. نحن أقلية عددية فقط، وهذا لا يجعلنا نشعر أن هناك شرخا بينا وبين إخواننا المسلمين كما أننا لا نشعر بشعور الأقلية البغيض

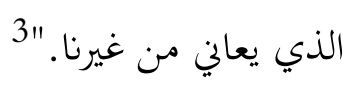

ومن الأمور الهامة، والجديرة بالملاحظة والاعتبار، أن تراثنا الإسلامي، الديني منه والحضاري والتاريخي، وكذلك اللغوي، لم يعرف استخدام مصطلح "الأقلية" بهذا المفهوم الوافد، وإنما عرفه فقط بمعناه اللغوي، أي الأقلية العددية، في مقابل الأكثرية العددية، دوما أي مفاضلة أو تمييز بسبب هذه الكثرة أو القلة في

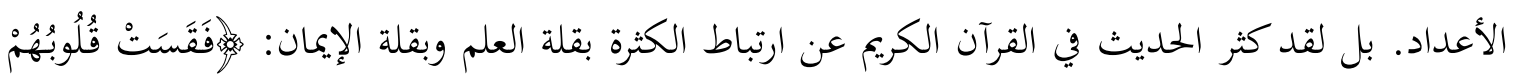

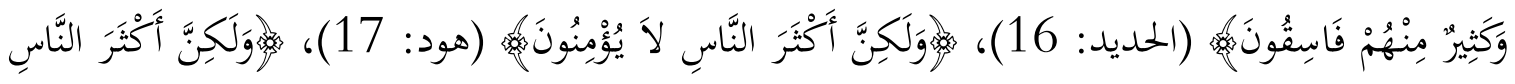
2 2 2 3 


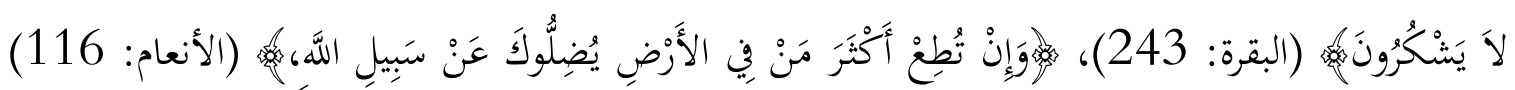

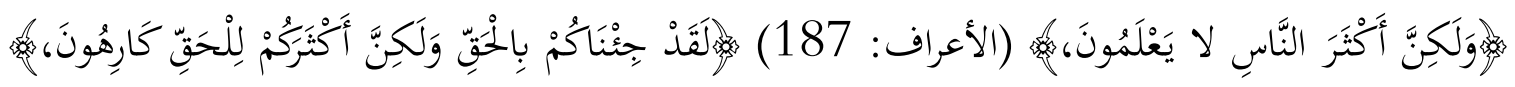
(الزخرف: 78)

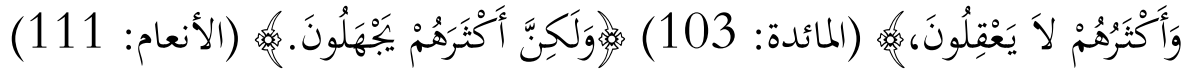

فلم تكن الكثرة ميزة دائما، بل لقد ارتبط مصطلحها، في الكثير من الاستخدامات، بالصفات السلبية. وعلى العكس من ذلك، ارتبط مصطلح القلة والأقلية -غالبا- في التعبيرات القرآنية بالصفات

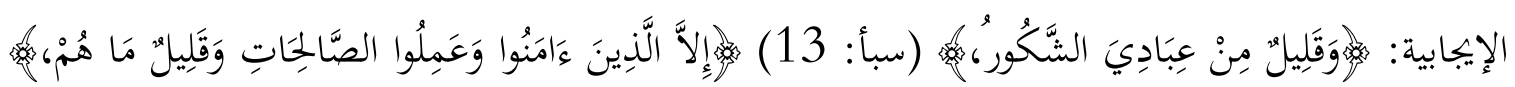

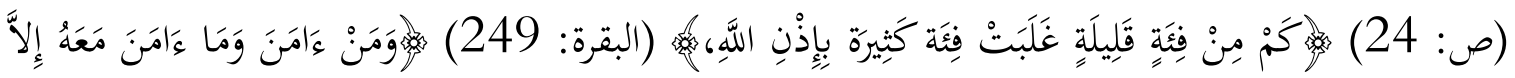

$$
\text { قَلِيلٌ. }
$$

فالأكثرية والأقلية مصطلحان يستخدمان بمعنى الكثرة العددية، فقط لا غير، دونما أية ظلال مفهومية لصيقة بالكثرة أو القلة، وإنما العبرة بالمعايير التي تجتمع عليها وتؤمن بها وتنتمي إليها الأكثريات والأقليات. فالمدح والذم، والإيجاب والسلب، والقبول والرفض إنما هو للمعايير والمكونات والهويات والمواقف، ولا أثثر في ذلك للكثرة أو القلة في الأعداد.

وانطلاقا من هذه الحقيقة رأينا الإسلام، وتراثه الفكري والحضاري، قد تميز عن الأنساق الفكرية، والحضارية التي مايزت بين الأعراق والأجناس، وأقامت علاقات "النفي للآخر" الديني واللغوي (القومي) فلقد نظر الإسلام، أولا بالدرجة الأولى، إلى (الجوامع) -الجامعة- وذلك دون أن يهمل "التمايزات" المميزة، وإنما سلك التمايزات والاختلافات في إطار الجوامع الموحدة، على نخو من الوسطية الجامعة، التي لا بتور على "الجوامع" فتؤدي إلى "التشرذم" والتشظي والتفرقة"، ولا تجور على "التمايزات والاختلافات" فتقضي إلى "قهر هذه التمايزات" ونفي الاختلافات.

فالإنسانية كلها قد خلقها الله، سبحانه وتعالى، من نفس واحدة، ثم شاء لها التنوع والاختلاف، إلى ذكرانٍ وإناث، وشعوبٍ وقبائل، وألسنة ولغات وقوميات، وألوان وأجناس، وملل ونحل وشرائع وأديان ومناهج وثقافات وحضارات، وأعراف وتقاليد وعادات، في إطار "جامع الإنسانية الواحدة". ونفس المنهاج، قد 
حكم الرؤية الإسلامية في النظر إلى "الأمة، ورعية الدولة." فجامع الأمة هو الرابط الذي يظل التنوع والاختلاف في العقائد والشرائع الدينية وف الشعوب والقبائل، وفي الألسنة واللغات والقوميات، وفي الطبقات الاجتماعية، وفي الأقاليم والأوطان، وفي العادات والتقاليد والأعراف -أي الثقافات الفرعية- كل هذا التنوع -الذي هو سنة من سنن الله التي لا تبديل لها ولا تحويل- يعيش ويزدهر في ظلال جوامع الأمة

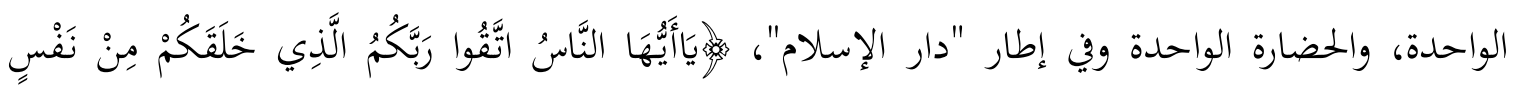

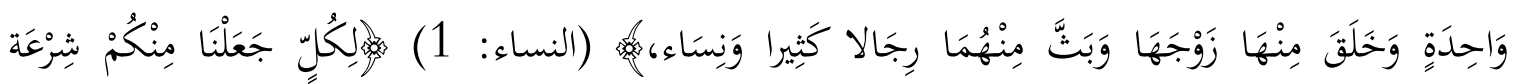

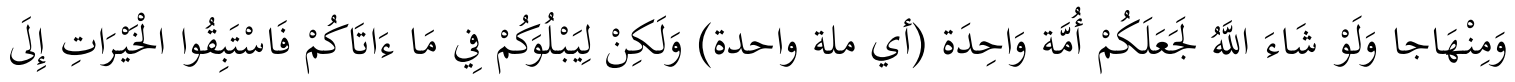

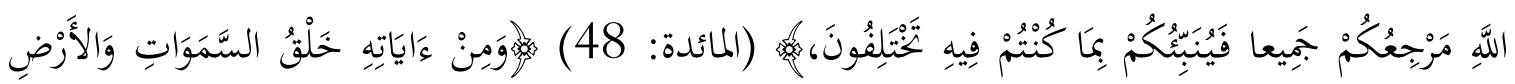

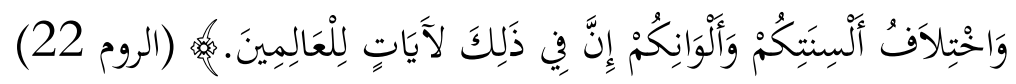

فكل هذه الأنواع من التمايزات هي القاعدة، والإعمال لسنة الله، سبحانه وتعالى، في كل عوالم الخلقى، ومن ثم فلا شبهة لوجود أية ظلال سلبية تنشأ بسبب أي تنوع أو اختلاف من هذه التمايزات، وبصرف النظر عن الأعداد التي ترتبط بأي لون من ألوان هذه الاختلافات. فهذه التمايزات إما أغا مؤسسة على صفات لصيقة، هي من صنع الله، أو على خيارات إنسانية، التعددية فيها سنة من سنن الله. هذا عن المفهوم الإسلامي لمصطلحات هذا المبحث -"الأقليات، والأكثريات"- وهو مفهوم لا علاقة له بالظلال التي ارتبطت هذه المصطلحات في السياق الحضاري الغربي، تلك التي ميزت بين الأغلبيات وبين الاثنيات العرقية، والألوان، والديانات، في المجتمعات الغربية.

أما إطار هذه الدراسة فهو: الأقليات غير المسلمة -النصرانية، واليهودية، والأرواحية (الوثنية)- في العالم الإسلامي، مع التركيز على مصر والوطن العربي كنموذج تطبيقي للمنهاج الإسلامي في النظر لهذا الموضوع. 
لقد مثل الإسلام -منذ ظهوره- "ثورة إصلاحية، وإصلاحا ثوريا" على المفاهيم السائدة التي حكمت علاقات الشعوب والأجناس والأديان في ذلك التاريخ.

فالرومان كانوا يحتكرون "السيادة" والشرف للجنس الروماني، ويرون في كل الآخرين والأغيار "برابرة" لا يستحقون حتى أن يطبق عليهم القانون الروماني، ولا حق لهم في التدين بغير دين السادة الرومان، وثنيا كان هذا الدين أو نصرانيا ملكانيا. ولقد صبوا جام اضطهادهم، في حقبة الوثنية، على اليهود وعلى النصارى، وفي حقبة تنصرهم الملكاني، على النصرانية الشرقية اليعقبية -في مصر والشام.

واليهودية التلمودية، قد تحولت إلى "إثنية- عنصرية"، بل و"وثنية" جعلت الله، سبحانه وتعالى، إله بنى إسرائيل وحدهم، وللشعوب الأخرى آلهتها، وذلك بدلا من الإيمان بأنه، سبحانه، هو إله العالمين ولقد صبوا جام اضطهادهم على المسيح عيسى بن مريم، عليه السلام، وعلى حوارييه والذين آمنوا به واتبعوه. والنصرانية هي الأخرى بادلت الآخرين إنكارا بإنكار، واضطهادا باضطهاد. فبمجرد أن أفاقت -في مصر مثلا- من الاضطهاد الوثني الروماني، وفور تدين الدولة الرومانية بالنصرانية، على عهد الإمبراطور "قسطنطين" (274-337م) صبت هذه النصرانية جام اضطهادها على الوثنية المصرية، فدمرت معابدها، وأحرقت مكتباتا، وسحلت فلاسفتها وقتلتهم ومزقتهم وأحرقتهم. وسجل التاريخ كيف قاد بطريرك الكنيسة المصرية "تيوفيلوس" (385-412م) حملة اضطهاد عنيفة ضد الوثنيين، واتجه للقضاء على مدرسة الإسكندرية، وتدمير مكتبتها وإشعال النار فيها، وطالت هذه الإبادة مكتبات المعابد، وتم السحل والتمزيق والحرق لفيلسوف الأفلاطونية الحديثة، وعالمة الفلك والرياضيات "إناتيه" (370 - 415م)، وذلك فضلا عن تحطيم التماثيل، والعبث بالآثار."

ثم عادت النصرانية اليعقبية إلى موقع الضحية واضطهدت من النصرانية الملكانية الرومانية، بعد الاختلافات حول طبيعة المسيح، عليه السلام.4 4

4 4 النقيوسي، يوحنا. تاريخ مصر. ترجمة ودراسة وتعليق عمر صابر عبد الجليل. القاهرة: عين شمس للدراسات والبحوث الإنمائية

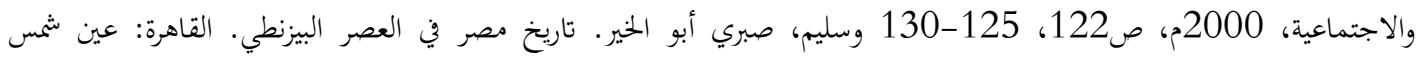

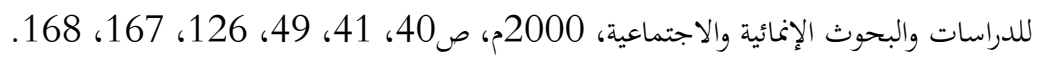


ولقد سجل القرآن الكريم هذه المواقف الرافضة لقبول الآخر، والتعايش معه، والتسامح مع تمايزاته

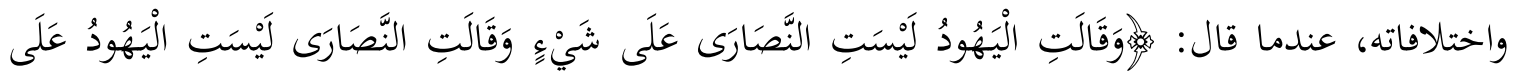

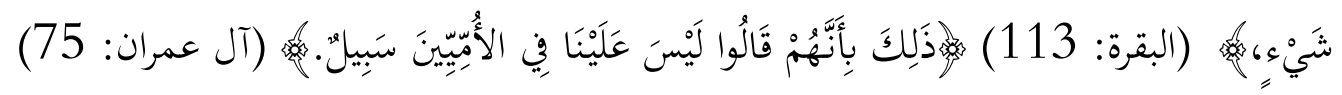
جاء الإسلام وهذا هو موقف الحكام من المحكومين، وموقف الأغلبيات من الأقليات، وموقف كل صاحب دين وهوية من الأغيار والآخرين. فمثّل وأحدث -منذ ظهوره، ومنذ إقامة دولته وأمته وحضارته"ثورة إصلاحية، وإصلاحا ثوريا" في هذه النظرات والعلاقات،. جاء الإسلام فسلك الاختلافات في إطار الوحدة، وجعل التنوع هو السنة والقاعدة والقانون، ووضعه لبنات في البناء الجامع،. وقرر أن "الآخر" هو جزء من "الذات"، وذلك لأول مرة في تاريخ الشرائع والأمم والدول والحضارات.

فالله، سبحانه وتعالى، هو ولهَرِِّ الْعَالَمِينَ، (الفاتحة: 2) وليس رب شعب دون غيره من الشعوب. وكل الشرائع الدينية، التي توالت على امتداد علاقة السماء بالأرض، هي تنوع في إطار الدين الإلهي الواحد

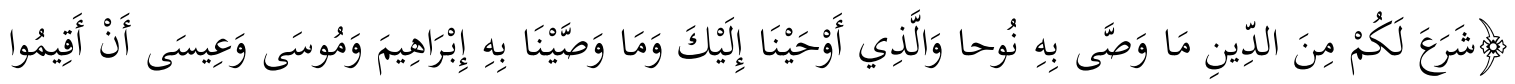

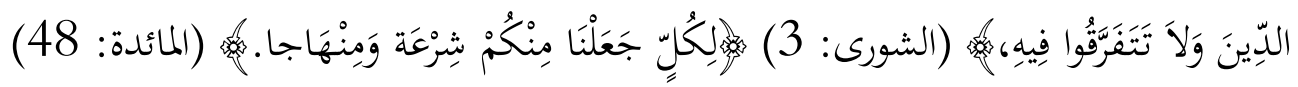

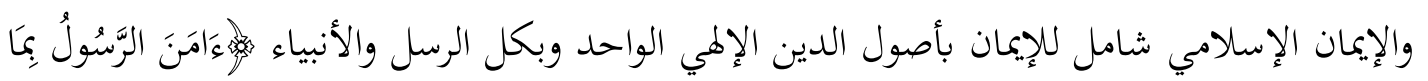

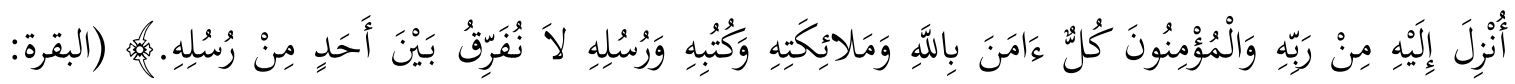
285) فجميع هؤلاء الرسل والأنبياء إنما يمثلون تنوع الشرائع الإلهية في إطار الدين الإلهي الواحد. "الأنبياء إخوة من غلاّت، أمهاقم شتى، ودينهم واحد" رواه البخاري ومسلم وأبو داود. والقرآن الكريم مصدق لما بين

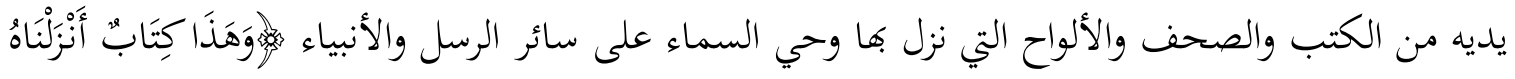

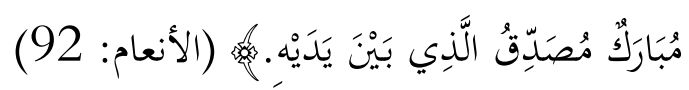
ورغم التحريف الذي أصاب بعض هذه الكتب السابقة، والنسيان الذي أصاب بعضها، ذهب القرآن - في الدقة والإنصاف- إلى تقرير أن هذا التحريف والنسيان لم يكونا عامين. ففي هذه الكتب -وخاصة

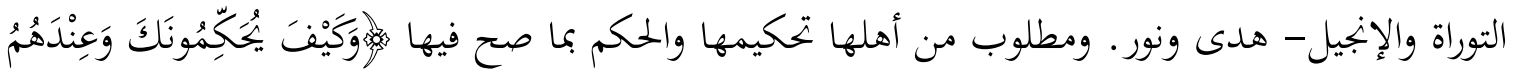




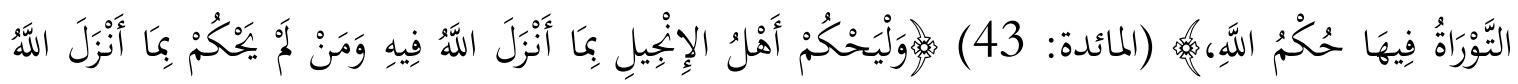

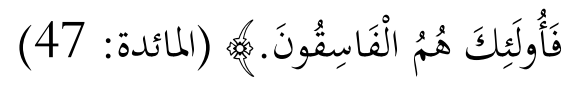

وحتى في الشرائع، المتمايزة بتمايز الأمم والرسالات والحقب التاريخية، لم يعمم الإسلام النسخ على

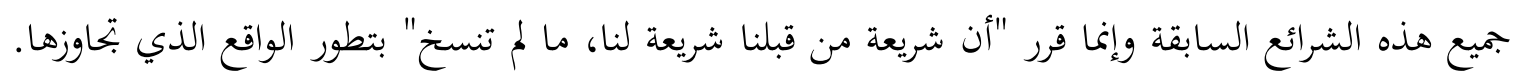

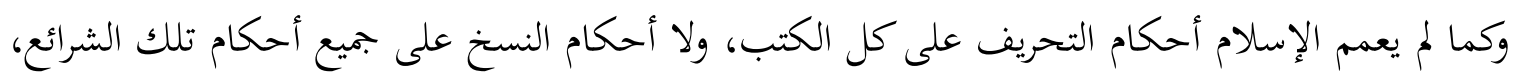

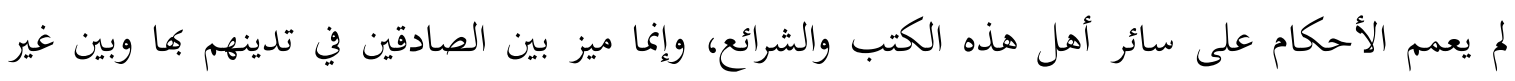

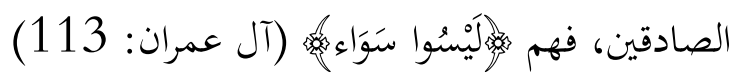

ولم يقف ذلك عند أحكام الدنيا ومعاملاتحا، بل قرر الإسلام -في أمر النجاة يوم الدين- أن الله لا

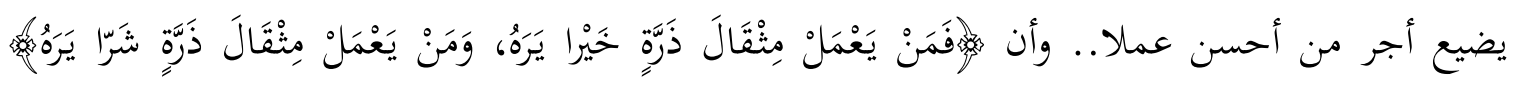
(الزلزة: 7-8). وأن الذين آمنوا بالتوحيد في الألوهية والربوبية، وبالغيب واليوم الآخر والحساب والجزاء،

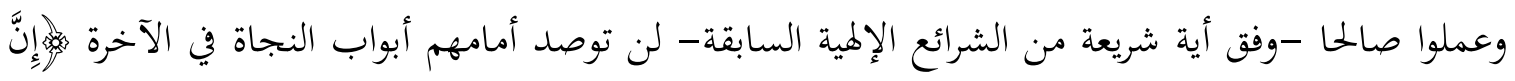

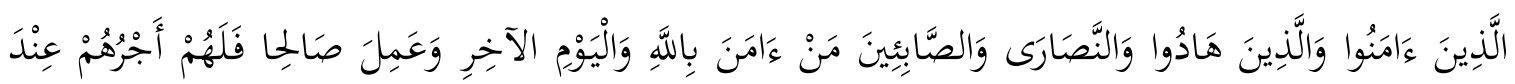

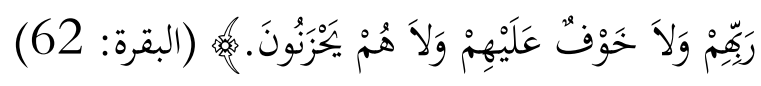

نعم، جاء الإسلام فأحدث هذه "الثورة الإصلاحية، والإصلاح الثوري" في العلاقة بالآخرين، وبلغ في

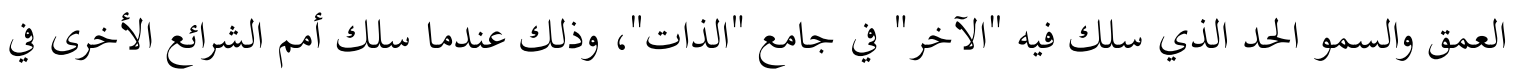

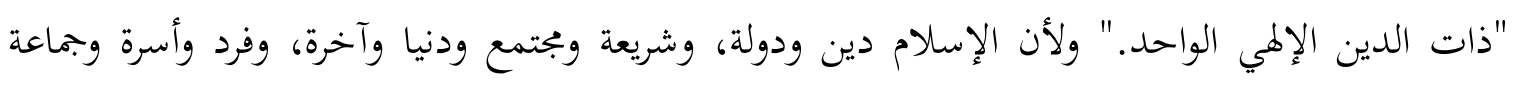

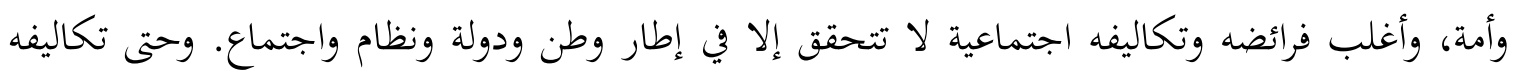

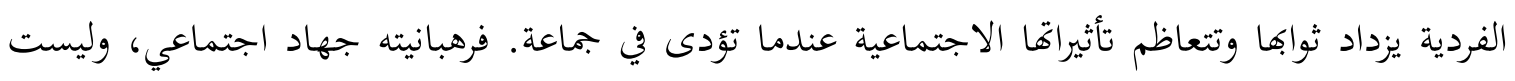

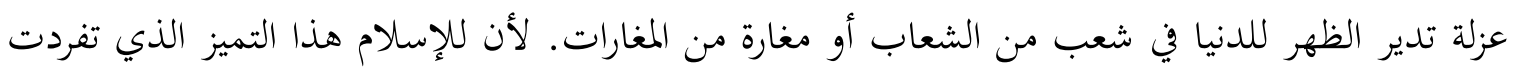

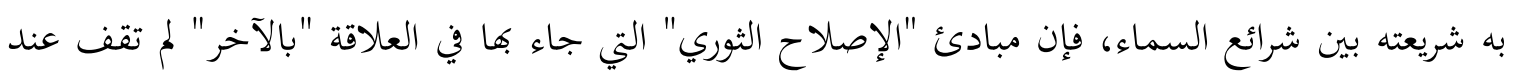

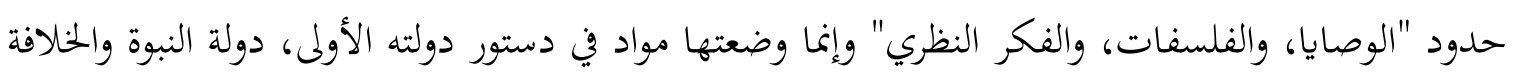

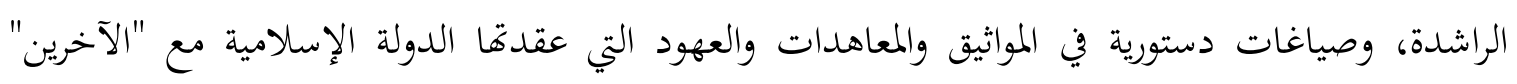


الذين قامت بينهم وبين دولة الإسلام علاقات ومصالح وارتباطات، ثم بتسد كل ذلك في الواقع والحضارة والتاريخ.

ففي دستور دولة المدينة - (الصحيفة، الكتاب) - الذي وضعه رسول الله صلى الله عليه وسلم، عند قيام هذه الدولة، عقب الهجرة، لينظم الحقوق والواجبات بين مكونات الأمة، في الوطن، نص هذا الدستور على أن القطاعات العربية المتهودة من قبائل المدينة، ومن لحق بهم وعاهدوه، قد أصبحوا جزءا أصيلا في الأمة الواحدة والرعية المتحدة لهذه الدولة الإسلامية. فنص هذا الدستور على أن "يهود أمة مع المؤمنين، لليهود دينهم ولممسلمين دينهم. ومن تبعنا من يهود فإن لهم النصر والأسوة، غير مظلومين ولا نتَنَاصر عليهم. وأن بطانة يهود ومواليهم كأنفسهم، وأن اليهود ينفقون مع المؤمنين ماداموا محاربين، على اليهود نفقتهم وعلى المسلمين نفقتهم، وأن بينهم النصر على من حارب أهل هذه الصحيفة. وأن بينهم النصح والنصيحة والبر المحصن من أهل هذه الصحيفة، دون الإثى، لا يكسب كاسب إلا على نفسه." وهكذا بتسد التحام "الآخر اليهودي" في الأمة الواحدة والرعية المتحدة للدولة، في ظل المرجعية الإسلامية، ومن خلال سعتها التي نص عليها هذا الدستور عندما قال: ".. وأنه لما كان من أهل هذه الصحيفة من حدث أو اشتجار يخاف فساده، فإن مرده إلى الله وإلى محمد رسول الله."6

كذلك تجسد هذه الالتحام "بالآخر"، وتحققت هذه المساواة وإياه في العلاقة التي أدخلت النصارى - نصارى "نجران" وكل المتدينين بالنصرانية -في صلب الأمة الواحدة، وفي رعية الدولة المتحدة، فنص ميثاق العهد الذي كتبه رسول الله صلى الله عليه وسلم، لنصارى "نجران" على بجموعة من المبادئ الدستورية التي وضعت مبادئ وفلسفات علاقة الإسلام "بالآخر" في الممارسة والتطبيق. فجاء في هذا الميثاق ".. ولنجران وحاشيتها، ولأهل ملتها ولجميع من ينتحل دعوة النصرانية. جوار الله وذمة محمد رسول الله على أموالهم، وأنفسهم، وملتهم، وغائبهم وشاهدهم، وعشيرتم، وبيعهم، وكل ما تحت أيديهم من قليل أو كثير أن أحمي ركي

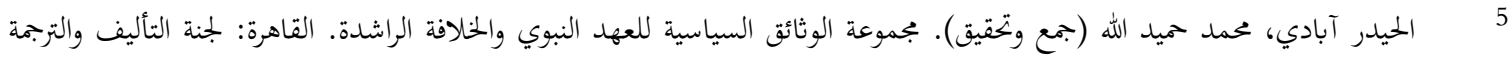

$$
\text { 6 }
$$


جانبهم، وأذب عنهم وعن كنائسهم وبيعهم وبيوت صلواتم، ومواضع الرهبان، ومواطن السياح، حيث كانوا من بر أو بحر، شرقا وغربا، بما احفظ به نفسي وخاصتي وأهل الإسلام من ملتي." ولم يقف هذا الميثاق، فقط، عند ضمان حرية الاختلاف في المعتقد الديني وحرية إقامة هذا المعتقد المخالف للإسلام. وإنما نص على احترام "الوجود المؤسسي" لهذا التنوع والاختلاف.. "فلا يغير أسقف من أسقفيته ولا راهب من رهبانيته."

ولأن "الجزية" هي "بدل جندية"، لا تؤخذ إلا من القادرين ماليا، الذين يستطيعون حمل السلاح وأداء ضريبة القتال دفاعا عن الوطن، وليست "بدلا من الإيمان بالإسلام" وإلا لفرضت على الرهبان ورجال الدين. وبدليل أن الذين اختاروا أداء ضريبة الجندية في صفوف المسلمين، ضد الفرس والروم، وهم على دياناتم غير الإسلامية -في الشام، والعراق، ومصر - لم تفرض عليهم الجزية، وإنما اقتسموا مع المسلمين الغنائم على قدم المساواة. لأن هذا هو موقع "الجزية" في علاقة الدولة الإسلامية بالآخرين، جاء في ميثاق نصارى "نجران": "ولا يحشرون (أي لا يكلفون التعبئة العامة للقتال)" ولا يكلف أحد من أهل الذمة منهم الخروج مع المسلمين إلى عدوهم، لملاقاة الحروب ومكاشفة الأقران، فإنه ليس على أهل الذمة مباشرة القتال، وإنما أعطوا الذمة على أن لا يكلفوا ذلك، وأن يكون المسلمون ذبابا عنهم، وجوارا دوفم ولا يُكرهوا على ته بتهيز أحد من المسلمين إلى الحرب الذي يلقون فيه عدوهم، بقوة وسلاح أو خيل، إلا أن يتبرعوا من تلقاء أنفسهم، فيكون من فعل ذلك منهم وتبرع به حُمد عليه، وعُرف له وكُوفئ به."

كما نص هذا الميثاق على أن العدل في القضاء والمساواة في تحمل الأعباء المالية إنما هي فريضة إلهية شاملة لكل الأمة، على اختلاف معتقداتما الدينية. "فلا خراج ولا جزية إلا على من يكون في يده ميراث من ميراث الأرض، ممن يجب عليه فيه للسلطان حق، فيؤدى ذلك على ما يؤتيه مثله، لا يجار عليه، ولا يُمَمل منه إلا قدر طاقته وقوته على عمل الأرض وعمارتحا وإقبال ثمرتا، ولا يُكلَّف شططاً ولا يُتجاوز به يه حد أصحاب الخراج من نظرائه، ولا يدخل شئ من بنائهم في شع من أبنية المساجد ولا منازل المسلمين، ومن سأل منهم حقا فبينهم النصف غير ظالمين ولا مظلومين.." 
أما الحرية الدينية والحق في المغايرة للإسلام، فلقد قدسها هذا الإسلام عندما نفى وجود الدين والتدين

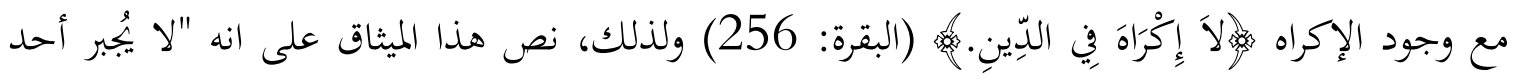
ممن كان على ملة النصرانية كرها على الإسلام، ولا تجادلوا أهل الكتاب إلا بالتي هي أحسن، ويُخضض لهم جناح الرحة، ويُكف عنهم أذى المكروه حيث كانوا وأين كانوا من البلاد."

وإمعانا من الإسلام في توفير عوامل التلاحم للأمة الواحدة، التي جعل الإسلام وحدقّا فريضة نص

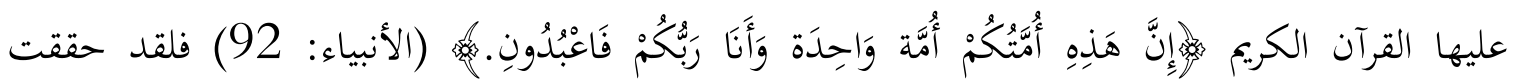
التطبيقات الإسلامية في الواقع الاجتماعي، عددا من الإنجازات التي سلكت الجميع في الأمة الواحدة. فالموالي، الذين كانوا أرقاء ثم حررهم الإسلام، دمجهم النظام الإسلامي في قبائلهم، التي كانوا أرقاء فيها، ولحمهم فيها بلحمة "الولاء"، الذي جعله كالنسب سواء بسواء، يكسب هؤلاء الموالي شرف هذه القبائل وحسبها ونسبها، ونصت سنة رسول الله صلى الله عليه وسلم، على أن "مولى القوم منهم." رواه البخاري وعلى أن "الولاء لحمة كلُحمة النسب" رواه الدارمي وأبو داود، حتى لقد أصبح بلال الحبشي (سيدا) يقول عنه عمر بن الخطاب، وعن أبى بكر الذي اشتراه وأعتقه "سيدنا أعتق سيدنا". وحتى لقد تمنى عمر أن يكون أحد الموالي، "سالم مولى أبي حذيفة" (12هـ/633م)، حيا ليجعله خليفة على المسلمين. والقبائل والعشائر، التي اندمج فيها الموالي، قد تحولت إلى لبنات في بناء الأمة الواحدة.

كذلك سلكت التطبيقات الإسلامية باب المصاهرة والزواج بين المسلمين وبين الكتابيات المحصنات لتحقيق أعلى درجات التلاحم بين غير المسلمين وبين المسلمين في بناء الأمة الواحدة. فزواج المسلم من الكتابية يدخل ذويها من غير المسلمين في دائرة "أولي الأرحام" عند المسلمين وتلك قمة التلاحم والاندماج، وعنها يقول الإمام محمد عبده (1265-1323ه) (1849هـ-1905م) أباح الإسلام للمسلم أن يتزوج الكتابية، نصرانية أو يهودية، وجعل من حقوق الزوجة الكتابية على زوجها المسلم أن تتمتع بالبقاء على عقيدتا والقيام بفروض عبادتا والذهاب إلى كنيستها أو بيعتها، وهي منه بمنزله البعض من الكل، وألزم له من الظل، وصاحبته في العز والذل، والترحال والحل، هججة قلبه، وريحانة نفسه، وأميرة بيته، وأم بناته وبنيه، تتصرف فيهم كما تتصرف فيه، لم يفرق الدين في حقوق الزوجية بين الزوجة المسلمة والزوجة الكتابية 


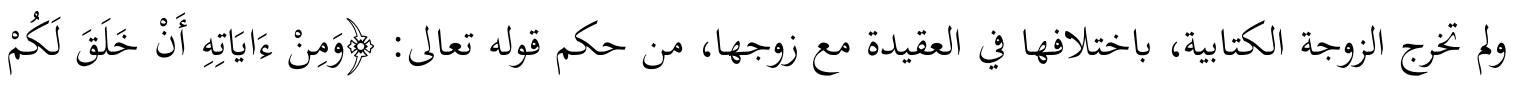

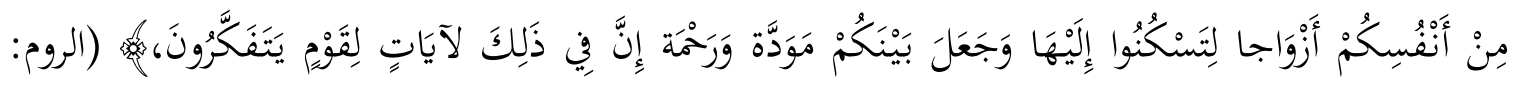

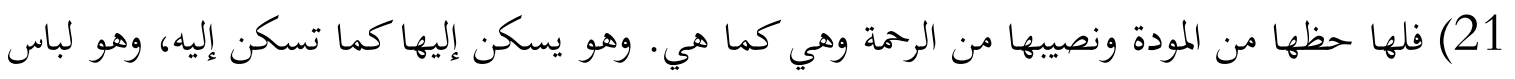

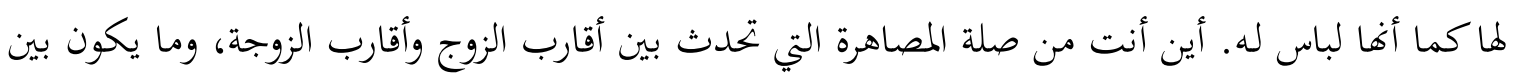

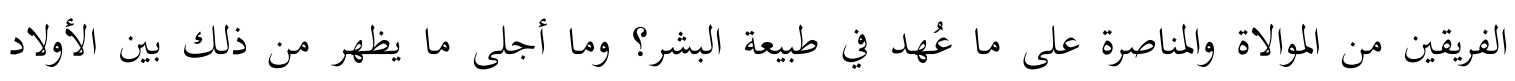

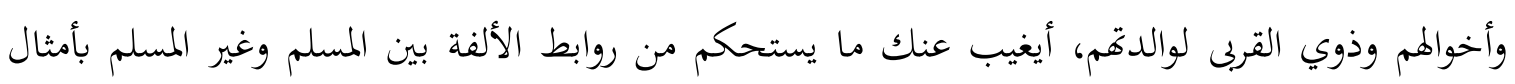

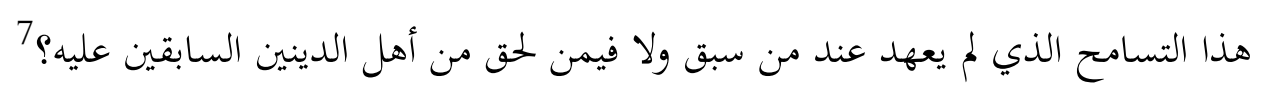

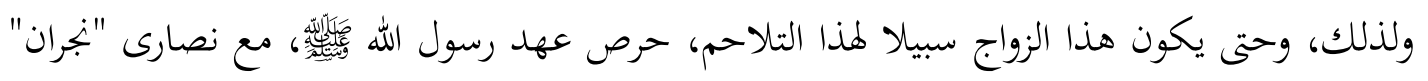

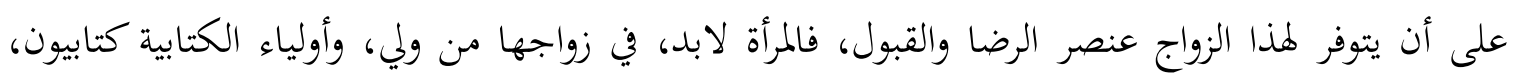

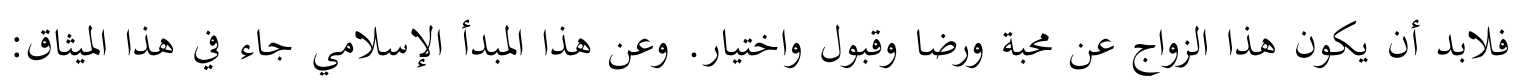

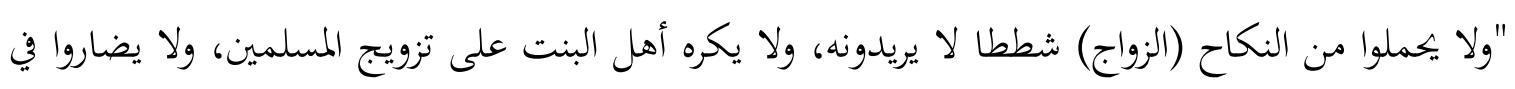

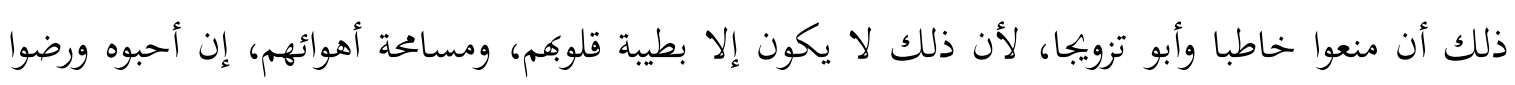
".

ولأن هذا التلاحم، بواسطة المصاهرة، لا يتحقق إلا في ظل الاعتراف الإسلامي "بالآخر الديني"،

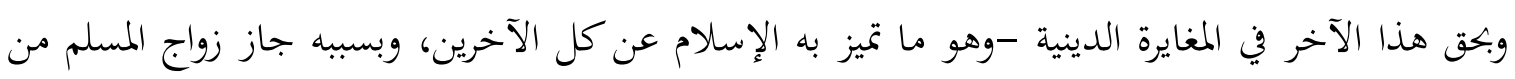

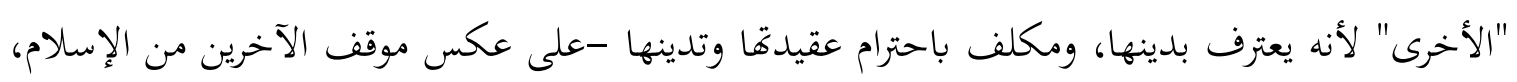

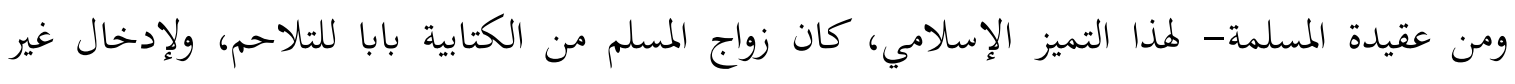

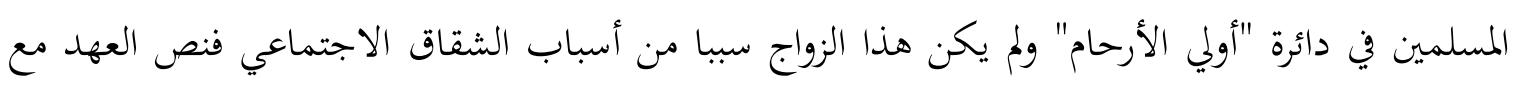

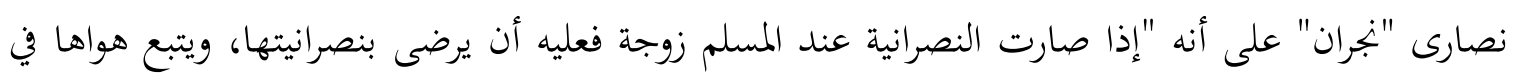

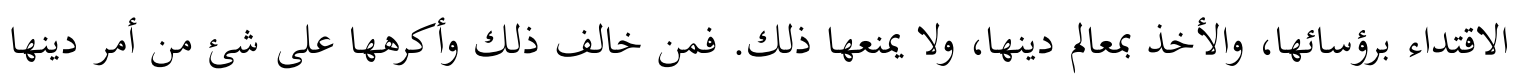

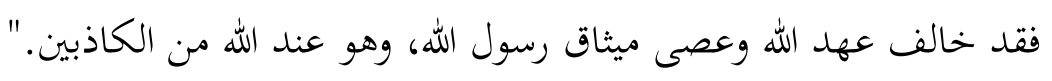
7 
وإذا كانت تطبيقات الدولة الإسلامية لهذه المبادئ الإسلامية، قد بلغت، وحققت، قبل أربعة عشر قرنا الحد الذي يدهش له الكثيرون في عصرنا الحاضر، من مثل تحرير جيش الفتح الإسلامي لمصر كنائس نصارى مصر من الاحتلال والاغتصاب الروماني، لا ليحولها إلى مساجد للمسلمين، وإنما ليردها للنصارى

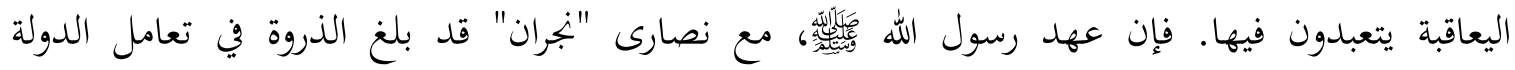
الإسلامية مع دور العبادة هذه - إلى الحد الذي نص فيه على أن مساعدة الدولة الإسلامية لغير المسلمين في بناء دور عبادتم هو جزء من واجبات هذه الدولة. فليست الواجبات فقط هي السماح ببناء دور العبادة وإنما هي أيضا الإعانة على بنائها. ولأن غير المسلمين هم جزء أصيل في الأمة الواحدة، والرعية المتحدة لهذه الدولة، فإن واجباها حيال دور عبادهم هي ذاتا الواجبات حيال مساجد المسلمين، فجاء في هذا الميثاق مع نصارى "نجران": ".. ولمم إن احتاجوا في مرمّة بيعهم وصوامعهم أو شئ من مصالح أمور دينهم، إلى رفد (مساعدة) من المسلمين وتقوية لمم على مرمتها، أن يُرفدوا على ذلك ويُعاونوا، ولا يكون ذلك دَيّنا عليهم بل تقوية لمم على مصلحة- دينهم، ووفاء بعهد رسول الله، وموهبة لهم، ومنّة له ورسوله عليهم." تم يتوج هذا الميثاق بنود هذه الحقوق بالنص على كامل المساواة بين المختلفين في الدين والمتحدين في الأمة الواحد والملتحمين في الرعية المتحدة للدولة الإسلامية، بقول رسول الله صلى الله عليه وسلم: ".. لأني أعطيتهم عهد الله أن لهم ما للمسلمين وعليهم ما على المسلمين وعلى المسلمين ما عليهم، حتى يكونوا للمسلمين شركاء فيما لهم وفيما عليهم."

ولأن وحدة الأمة لا تتحقق إلا بولاء كل أبنائها لها وانتماء جميعهم لدولتها ولمقومات هويتها وأمنها الوطني والقومي والحضاري، اشترط هذا العهد على نصارى "نجران" أن يكون الولاء خالصا والانتماء كاملا لهذه الأمة الواحدة ولهذه الدولة الإسلامية. فالولاء - كل الولاء- لها وحدها، والبراء -كل البراء- من جميع أعدائها. ولذلك، جاء في هذا الميثاق: "واشترط عليهم أمورا يجب عليهم في دينهم التمسك بها والوفاء بما عاهدهم عليه، منها: ألا يكون أحد منهم عينا ولا رقيبا لأحد من أهل الحرب على أحد من المسلمين في سره وعلانيته، ولا يأوي منازهم عدو للمسلمين، يريدون به أخذ الفرصة وانتهاز الوثبة، ولا ينزلوا أوطافم ولا ضياعهم ولا في شئ من مساكن عباداتم ولا غيرهم من أهل الملة ولا يرفدوا (يساعدوا) أحدا من أهل الحرب 
على المسلمين، بتقوية لهم بسلاح ولا خيل ولا رجال ولا غيرهم ولا يصانعوهم. وإن احتيج إلى إخفاء أحد من المسلمين عندهم، وعند منازهم، ومواطن عبادتم، أن يؤوهم ويرفدوهم ويواسوهم فيما يعيشون به ما كانوا

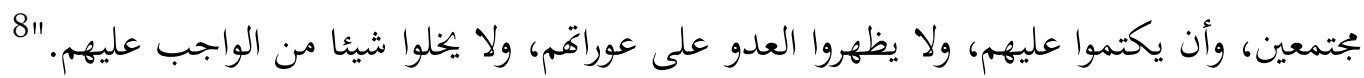

ويزيد من سمو هذا الإنجاز الإسلامي، تعميم التطبيقات الإسلامية لذذا المنهاج وهذه المبادئ على

الديانات الوضعية أيضا. فلم يقف المسلمون بهذه "الثورة الإصلاحية" في العلاقة بالآخر، عند اليهود -أهل التوراة- والنصارى -أهل الإنجيل- فقط، وإنما عمموها لتشمل "المجوس" و"الهندوس" و "البوذيين". وعندما فتح المسلمون فارس -وأهلها بجوس يعبدون النار، ويقولون بإلهين أحدهما للخير والنور وثانيهما للشر والظلمة- عرض أمير المؤمنين عمر بن الخطاب (40 قه-23 هـ/ 584-644م) هذا الأمر، و"الواقع المستجد على مجلس الشورى- في مسجد المدينة وقال:

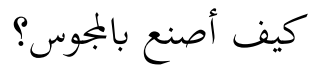

$$
\begin{aligned}
& \text { فوثب عبد الرحمن بن عوف (رضي الله عنه) (44 ق هـ-32هـ/ 580-652م) فقال: } \\
& \text { أشهد على رسول الله صلى الله عليه وسلم، أنه قال: "سُنُّا فيهم سنَّةَ أهل الكتاب."9 }
\end{aligned}
$$

فطبقت الخلافة الراشدة هذه السنة النبوية، وساد هذا التطبيق على امتداد تاريخ الإسلام في بلاد الديانات الوضعية من فارس إلى الهند إلى الصين، حتى لقد تمتع أهل هذه الديانات، لا بحرية الاعتقاد فقط، وإنما -أيضا- بحرية مناظرة علماء الإسلام في مجالس الخلفاء، إبان مجد وقوة وعظمة الخلافة الإسلامية. ولقد أورد "السير توماس أرنولد" (1864-1930) -بإعجاب- كيف أن زعيم المانوية10 المجوس -في فارس"يزدانبخت" قد أتى بغداد، وناظر المتكلمين المسلمين في حضرة الخليفة المأمون (170-218هـ/786833م) فلما أفحمه علماء الإسلام تاق المأمون إلى أن يسلم "يزد انبخت"، ففاتحه في ذلك، لكنه رفض، في أدب، وقال للخليفة: نصيحتك، يا أمير المؤمنين، مسموعة، وقولك مقبول، ولكنك من لا يجبر الناس

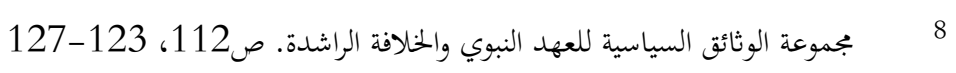

$$
\begin{aligned}
& 9 \text { و } 9 \\
& 10
\end{aligned}
$$


على ترك مذهبهم فتركه المأمون وشأنه، بل وطلب حمايته من العامة حتى يبلغ مأمنه بين أتباعه وأنصار مذهبه من المجوس. 11 وهكذا بلغ الإسلام القمة، عندما لم يكتف بالوصايا والمنظومة الفكرية والفلسفية، التي تعترف بالآخر - الذي لا يعترف بالإسلام: وإنما بحاوز "الفكر" إلى "الممارسة والتطبيق"، في الدولة، والأمة،

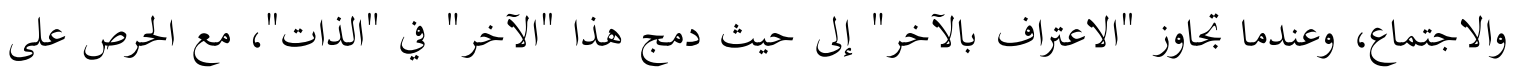
التعددية الدينية، التي سلكها في إطار "وحدة الدين" الإلهي الواحد لا باعتبارها بجرد حق من حقوق الضمير الإنساني، وإنما باعتبارها سنة من سنن الله التي لا تبديل لها ولا تحويل، فحقق الإسلام بهذا "الإصلاح الثوري" مستوى غير مسبوق في التاريخ الإنساني، إن على المستوى الفكري أو في الممارسة والتطبيق.

وإذا كانت سنة من سنن الله، في الاجتماع الإنساين، أن يكون هناك -دائما وأبدا- فارق بين "الواقع" وبين "المثال" وأن يظل "المثال" -دائما وأبدا- عصيا على كمال التحقق في "الواقع" المعين. فإن ممارسات الدولة الإسلامية والمجتمعات الإسلامية لم تكن دائما على مستوى هذا "المثال" الإسلامي في العلاقة مع "الآخر" الديني. كما أن هذا "الآخر" الديني لم يكن -دائما وأبدا- على مستوى هذا "المثال" الذي نصت عليه العهود والمواثيق أو لنقل لم يكن كل المسلمين ولا كل الحكام على مستوى هذا "المثال." ولم يكن كل غير المسلمين على مستوى هذا "المثال"، لكن -ومع ذلك- ظلت هناك ثوابت حكمت علاقة المسلمين بغير المسلمين، في الدولة الإسلامية والمجتمعات الإسلامية عبر تاريخ الإسلام. فلم يعرف هذا التاريخ الإسلامي إكراها في الدين. فلقد دخل الشرق -بالفتوحات الإسلامية- في الدولة الإسلامية خلال سنوات قياسية في تاريخ الفتوحات، إذ فتح المسلمون في ثمانين عاما أوسع مما فتح الرومان في ثمانية قرون. ولقد كانت هذه الفتوحات الإسلامية تحريرا للشرق -الإنسان والأرض- من القهر الديني والحضاري الذي مارسه الرومان والفرس ضد شعوب الشرق على امتداد عشرة قرون، من الاسكندر الأكبر (356-324 ق.م) في القرن الرابع قبل الميلاد، إلى الفتوحات الإسلامية، في القرن السابع للميلاد. فترك الناس وما يدينون دونما إكراه، بل وفى أحيان كثيرة دونما ترغيب عندما كان بعض الولاة أحرص على تي أرنولد، سير توماس. الدعوة إلى الإسلام. ترجمة: حسن إبراهيم حسن وآخرين، القاهرة: لجنة التأليف والتربمة والنشر، 1970م، 
الجزية منهم على إسلام غير المسلمين: حتى أن أقليات اليوم الدينية -وخاصة النصرانية- قد ظلت أغلبيات غير مسلمة في الدولة الإسلامية لعدة قرون.

وإذا أخذنا مصر نموذجا - وهي التي ضربت المثل الأروع في الاستمساك بنصرانيتها على امتداد ستة قرون من الاضطهادات الرومانية التي ضربت بها الأمثال- فإننا نجد أن تحول أغلبية أهلها إلى الإسلام، قد استغرق عقودا طويلة. فلقد كان تعداد سكاغا، من النصارى واليهود، عند الفتح الإسلامي ها (سنة 20هـ/641م) 2.500.000 نسمة. وحتى غاية خلافة "معاوية بن أبي سفيان" (20قهـ-60هـ/603680م) -أي بعد نهو نصف قرن من الفتح الإسلامي- كان قرابة نصف المصريين لا يزالون على

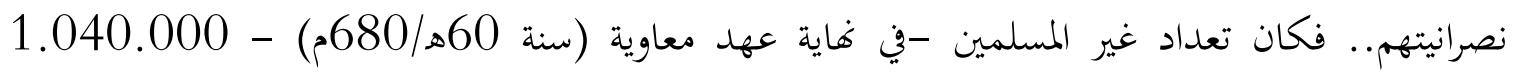
نسمة. وفن غاية عهد هارون الرشيد (149-193ه/766-809م) - أي بعد مرور قرابة القرنين من الزمان على تاريخ الفتح -، كان تعداد غير المسلمين بمصر 650.000 نسمة، أي نهو ربع السكان، البالغ عددهم يومئذ 2.671.000 نسمة. وحتى القرن التاسع الميلادي -أي بعد قرنين ونصف من الفتح الإسلامي لمصر- كانت نسبة غير المسلمين في سكاغا 20\% من هؤلاء السكان، 12 الأمر الذي يقدم الحقائق المادية -بالأرقام- لهذه الخلاصة التي كتبها المستشرق الإنجليزي -الحجة والشديد التدين بالنصرانية"سير توماس أرنولد"، والتي قال فيها: "إنه من الحق أن نقول: إن غير المسلمين قد نعموا، بوجه الإجمال، في ظل الحكم الإسلامي، بدرجة من التسامح لا نجد لها معادلا في أوربا قبل الأزمنة الحديثة. وإن دوام الطوائف المسيحية في وسط إسلامي يدل على أن الاضطهادات التي قاست منها بين الحين والآخر على أيدي المتزمتين والمتعصبين كانت من صنع الظروف المحلية، أكثر مما كانت عاقبة مبادئ التعصب وعدم التسامح."13

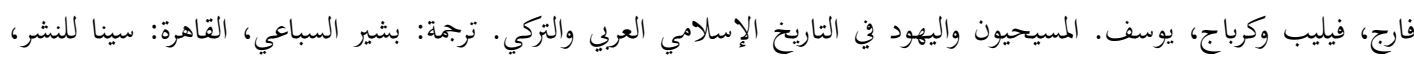

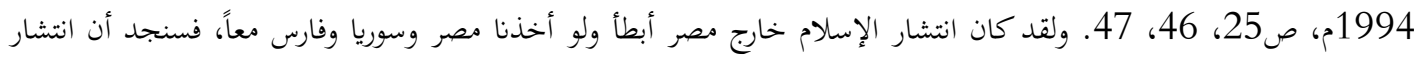

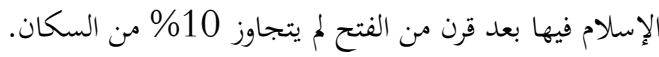

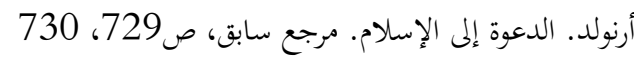


فلم يكن هناك إكراه على التحول إلى الإسلام، بل لم تكن للإسلام، عبر تاريخه "مؤسسة تبشيرية"

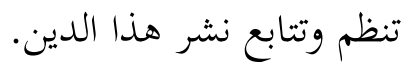

وأكثر من ذلك، فلقد كتب علماء وباحثون من النصارى الغربيين، عن تحولات الأغلبيات النصرانية الشرقية إلى الإسلام، فأرجعوا هذه التحولات إلى اختلافات الكنائس النصرانية حول طبيعة المسيح، عليه السلام، تلك الاختلافات التي حولت العقيدة النصرانية إلى أسرار وألغاز جعلتها مستعصية على فهم الجمهور، فلما أشرقت شمس التوحيد الإسلامي، على هذا النحو البسيط والفطري، تحولت أغلبيات نصارى الشرق إلى هذا التوحيد، عن رغبة، ولإشباع الروحي، ولخلو الإسلام من سلطة الكهنوت التي تحتكر مفاتيح التوبة والخلاص، تحولت هذه الأغلبيات -لذلك- نحو الإسلام دونما إكراه، بل ولا حتى ترغيب. كتب عن هذه الحقيقة علماء نصارى، منهم "كيتانين Caetanin الذي يقول: "إن انتشار الإسلام بين نصارى الكنائس الشرقية إنما كان نتيجة شعور باستياء من السفسطة المذهبية التي جلبتها الروح الهلينية إلى اللاهوت المسيحي. أما الشرق، الذي عرف بحبه للأفكار الواضحة البسيطة، فلقد كانت الثقافة الهيلينية وبالا عليه من الوجهة الدينية، لأها أحالت تعاليم السيد المسيح عليه السلام البسيطة السامية إلى عقيدة محفوفة بمذاهب عويصة، مليئة بالشكوك والشبهات، فأدى ذلك إلى خلق شعور من اليأس، بل زعزع أصول العقيدة الدينية ذاها. فلما أهلّت آخر الأمر أنباء الوحي الجديد فجأة من الصحراء لم تعد تلك المسيحية الشرقية، التي اختلطت بالغش والزيف، وتزقت بفعل الانقسامات الداخلية وتزعزعت قواعدها الأساسية، واستولى على رجالها اليأس والقنوط من مثل هذه الزّيب، لم تعد المسيحية بعد تلك قادرة على مقاومة إغراء هذا الدين الجديد الذي بدد بضربة من ضرباته كل الشكوك التافهة، وقدم مزايا جليلة، إلى جانب مبادئه الواضحة البسيطة التي لا تقبل الجدل. وحيئذ ترك الشرق المسيح وارتمى في أحضان نبي العرب." لقد أقبل الناس على الإسلام، الذي رأوه -كما يقول "مونتيه"- "عقلاني الجوهر، بأوسع معاني هذه

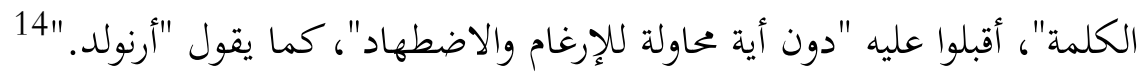


والثابت الثالث من ثوابت علاقة الإسلام بغير المسلمين، في الدولة الإسلامية والمجتمعات الإسلامية، هو استمرار غير المسلمين قابضين على عصب دواوين الدولة الإسلامية وإداراتا قبل تعريب لغة تلك الدواوين وبعد تعريبها (سنة 87هـ/705م) وهذه الحقيقة جعلت المستشرق الألماني الحجة "آدم متز" (1869-1917م) يكتب فيقول: "لقد كان النصارى هم الذين يجكمون بلاد الإسلام."15 ومن يراجع كتاب (الإشارة إلى من نال الوزارة) لابن الصيرفي يرى حجم السيطرة غير المسلمة على مناصب الوزارة والإدارة عبر تلك القرون. 16 أما التوترات الطائفية التي شهدةا المجتمعات الإسلامية، والتي ألحقت قدرا من الضيق والتضييق والتمييز والأذى بالأقليات غير الإسلامية، فلقد كانت عارضة وعابرة. وكانت أغلب أسباهما وافدة على الموقف الإسلامي الثابت والأصيل، ومفروضة على المنهاج الطبيعي للتطبيقات الإسلامية لهذا المنهاج.. وبعبارة "سير توماس أرنولد": فلقد كان مرد هذه الاضطهادات إلى "ظروف محلية" أكثر مما كانت ثمرة لمبادئ التعصب وعدم التسامح. أما هذه الأسباب الطارئة على الإسلام، والمفروضة على منهاج المسلمين في معاملة الآخر الديني، فلقد فصلها وحصرها باحث ومؤرخ نصراين لبناني، هو الدكتور "جورج قرم"، عندما قال: "إن فترات التوتر والاضطهاد لغير المسلمين في الحضارة الإسلامية كانت قصيرة وكان يحكمها ثلاثة عوامل: أولها مزاج الخلفاء الشخصي، فأخطر اضطهادين تعرض لمما الذميون وقعا في عهد المتوكل (206-247هـ / 821-861م) الخليفة الميال بطبعه إلى التعصب والقسوة. وفي عهد الخليفة الحاكم بأمر الله (375-411هـ/9851021م) الذي غالى في التصرف معهم بشدة (وكلا هذين الحاكمين عم اضطهادهما المسلمين وغير المسلمين)؛ والعامل الثاني هو تردي الأوضاع الاقتصادية الاجتماعية لسواء المسلمين، والظلم الذي يمارسه

متز، آدم. الحضارة الإسلامية في القرن الرابع الهجري. ترجمة: عمد عبد المادي أبو ريدة، بيروت: دار الكتاب العربي، 1967م، ج 1، ص105 بن منجب، أبو القاسم (الشهير بابن الصيري). الإشارة إلى من نال الوزارة. تعقيق: عبد الله خخلص، القاهرة: مطبعة المعهد العلمي

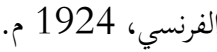
أرنولد، سير توماس. الدعوة إلى الإسلام. مرجع سابق، ص729، 730 
بعض الذميين المعتلين لمناصب إدارية عالية، فلا غرابة أن ندرك صلتهما المباشرة بالاضطهادات التي وقعت في عدد من الأمصار. أما العامل الثالث فهو مرتبط بفترات التدخل الأجنبي في البلدان الإسلامية، وقيام الحكام الأجانب بإغراء الأقليات الدينية غير المسلمة واستدراجها إلى التعاون معهم ضد الأغلبية المسلمة. إن الحكام الأجانب بمن فيهم الإنجليز لم يحجموا عن استخدام الأقلية القبطية في أغلب الأحيان ليحكموا الشعب ويستنزفوه بالضرائب -وهذه ظاهرة نلاحظها في سوريا أيضا، حيث أظهرت أبحاث "جب" و"بولياك" كيف أن هيمنة أبناء الأقليات في الجمال الاقتصادي أدت إلى إثارة قلاقل دينية خطيرة بين النصارى والمسلمين في دمشق سنة 1860م وبين الموارنة والدروز في جبال لبنان سنة 1840م وسنة 1860م. وفاية الحملات الصليبية قد أعقبتها في أماكن عديدة، أعمال ثأر وانتقام ضد الأقليات المسيحية - ولا سيما الأرمن- التي تعاونت مع الغازي.

بل إنه كثيرا ما كان موقف أبناء الأقليات أنفسهم من الحكم الإسلامي، حتى عندما كان يعاملهم بأكبر قدر من التسامح، سببا في نشوب قلاقل طائفية، فعلاوة على غلو الموظفين الذميين في الابتزاز، وفي مراعاهم وتحيزهم، إلى حد الصفاقة، أحيانا، لأبناء دينهم، ما كان يندر أن تصدر منهم استفزازات طائفية بكل معنى الكلمة.

وإذا شئنا الإشارة إلى وقائع من التاريخ -الوسيط والحديث- تؤكد صدق هذا التحليل الذي قدمه الدكتور "جورج قرم" لأسباب التوترات الطائفية العارضة، وخاصة بسبب الغوايات الاستعمارية لبعض أبناء الأقليات الدينية، فإن هناك واقعة دالة إبان الغزوة التترية، عندما استقوى نصارى دمشق بالقائد التتري "كتبغا" -وكان نصرانيا نسطوريا- فانحازوا للغزاة ضد المسلمين، وتحولوا إلى أداه إذلال واضطهاد للمسلمين في ظل الاحتلال التتري. ولقد تحدث مؤرخ العصر المقريزي (766-845هـ /1365-1441م) عن هذا الاستعلاء والاستقواء النصراني بالتتار، فقال: "واستطال النصارى بدمشق على المسلمين، واحضروا فرمانا من "هولاكو" بالاعتناء بأمرهم وإقامة دينهم، فتظاهروا بالخمر في غار رمضان، ورشوه على ثياب المسلمين في الطرقات، وصبوه على أبواب المساجد، وألزموا أرباب الحوانيت بالقيام إذا مروا بالصليب عليهم، وأهانوا من

قرم، جورج. تعدد الأديان ونظم الحكم: دراسة سوسيولوجية وقانونية مقارنة. بيروت: دار النهار، 1979، ص211 219-224 والنص في

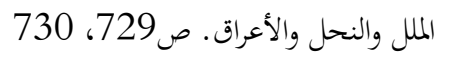


امتنع عن القيام للصليب، وصاروا يمرون به في الشوارع إلى كنيسة مريم، ويقفون به ويخطبون في الثناء على دينهم، وقالوا جهرا " ظهر الدين الصحيح، دين المسيح"، وخربوا مساجد ومآذن كانت بجوار كنائسهم فقلق المسلمون من ذلك، وشكوا أمرهم لنائب "هولاكو" -وهو " كتبغا"- فأهاغم وضرب بعضهم، وعظم قدر قسوس "النصارى" ونزل إلى كنائسهم وأقام شعارهم!

وأمام هذه الخيانة، والاحتماء بالعدو الغازي وإهانة واضطهاد الأقلية للأغلبية، ما كان من السلطان "قطز" (658هـ/1260م) إلا أن أوقع بنصارى دمشق، وترك الناس "فخربوا دورهم وغبوها"19 عقب وكن الانتصار على التتار في عين جالوت (658هـ/1260م). ولقد تكرر مشهد الغواية والخيانة في مطلع العصر الحديث عندما جاء بونابرت (1769-1821م) على رأس الحملة الفرنسية لغزو مصر (17213ه8/1)، وألقى حبال الغواية لأبناء الأقليات الدينية، ووقع في هذه الحبال نفر من أقباط مصر، خانوا أمتهم وطائفتهم وكنيستهم. قادهم " المعلم يعقوب حنا" (1745-1801م) وكونوا فيلقا قبطيا تزيّا بزي الجيش الفرنسي، وحارب المصريين وأذلهم لحساب الفرنسيين. ولقد تحدث مؤرخ العصر الجبرتي (1167-1237هـ/1754-1822م) عن صنيع "بونابرت" مع هذه القلة الخائنة، عندما جعل لهم نصف عضوية "ديوان المشورة"، والسلطة الفعلية في الجهاز المالي والإداري وبعبارة الجبرتي، فلقد فوض الجنرال كليبر (1753-1800م) للجنرال يعقوب "أن يفعل بالمسلمين ما يشاء حتى تطاول النصارى من القبط ونصارى الشوام على المسلمين بالسب والضرب ونالوا منهم أغراضهم وأظهروا حقدهم، ولم يبقوا للصلح

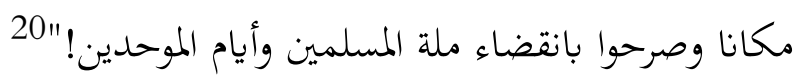

فكان السقوط في شراك الغواية الاستعمارية من أكثر أسباب التوتر الطائفي تأثيرا في الفترات العارضة التي شابت فيها هذه التوترات تلك الوحدة التي حققها الإسلام مع الآخر الديني في الأمة، والدولة، ومقومات الهوية الوطنية والحضارية على امتداد تاريخ الإسلام.

المقريزي، أبو العباس تقي الدين. (المتوفي 845 هـ) كتاب السلوك لمعرفة دول الملوك. القاهرة: لجنة التأليف والترجمة والنشر، 1956م، ج 1، ق 2، ص4325، 4325 تحقيق: محمد مصطفى زيادة. الجبرتي. عجائب الآثار في التراجم والأخبار. تحقيق: حسن محمد جوهر وآخرين، القاهرة: لجنة البيان العربي، 1965م، ج 5، 


\section{ثالثا :الواقع المعاصر للأقليات والتحديات الخيطة بها}

لقد تعمدنا في هذه الدراسة أن يكون الرجوع دائما إلى المصادر المتخصصة، والمعتمدة، والتي كتبها علماء وباحثون مشهود لهم بالأمانة والموضوعية ورسوخ القدم في تخصصاتم. وتعمدنا كذلك، عندما نكون بإزاء قضية خلافية يدور حولها جدل كثير وكبير أن تكون المصادر التي نحتكم إليها قد كتبها علماء وباحثون غير مسلمين!

صنعنا ذلك ونحن نبحث عن مكانة غير المسلمين ونفوذهم وموقعهم في الحضارة والتاريخ والدول والمجتمعات الإسلامية وكذلك عند بحث أسباب التوترات الطائفية التي مرت بها الأقليات غير المسلمة في

$$
\text { بعض فترات التاريخ الإسلامي ببعض المجتمعات الإسلامية. }
$$

ونصنع ذلك الآن، ونحن نريد حسم قضية يثور حولها جدل كبير وتشكيك كثير، وهي قضية عدد الأقليات غير المسلمة في أقطار الوطن العربي خاصة، ودول العالم الإسلامي بوجه عام.

أما المصادر المتخصصة في السكان "الديموجرافيا"، والتي كتبها علماء وباحثون غير مسلمين، والتي اعتمدنا عليها في حسم هذه القضية المثيرة للجدل فهي: (أطلس معلومات العالم العربي) الذي كتبه اللبناني المسيحي "رفيق البستاني" والفرنسي المسيحي "فيليب فارج" والمطبوع سنة 1994م، وكذلك كتاب (المسيحيون واليهود في التاريخ الإسلامي العربي والتركي) الذي كتبه عالمان متخصصان في "الديموجرافيا" والصادر عن مؤسسة فرنسية متخصصة في الأبحاث والدراسات "الديموجرافية" هما "فليب فارج" و"يوسف كرباج" المطبوعة ترجمته العربية سنة 1994م. وكلا المصدرين تتابع إحصاءاهما الواقع "السكانيالديموجرافي" حتى سنوات الطبع، أي ما يقرب من منتصف تسعينيات القرن العشرين.

من خلال هذه المصادر العلمية المتخصصة فإن تعداد النصارى العرب، في كل أقطار الوطن العربي بمذاهبهم وطوائفهم وكنائسهم المختلفة حوالي سبعة ملايين نسمة. وأن متوسط نسبة النصارى في سكان الشرق الأوسط -العرب وتركيا- هو 3.8\%. أما تعداد اليهود في أقطار الوطن العربي فهو 13.000 
نسمة - في بعض الإحصاءات و20.000 نسمة في إحصاءات أخرى- ولعل السبب في الاختلاف هو الهجرات المتحركة لمذه الأقليات اليهودية نهو إسرائيل.

$$
\text { ويبلغ تعداد الأقليات الارواحية (الوثنية) في جنوب السودان } 5.800 .000 \text { نسمة. }
$$

ولما كان الجدل الأكثر في إحصاء أعداد غير المسلمين إنما يدور حول عدد الأقباط النصارى في مصر والذين يمثلون أكبر الأقليات النصرانية في الواقع العربي فلقد اهتمت هذه المصادر المتخصصة بالوقوف عندها وحسم قضية تعدادها ولقد جاء في (أطلس معلومات العالم العربي) ص 32 تحت عنوان أقباط مصر ما يلي: كم عددهم؟ كم عدد أكبر طائفة مسيحية في الشرق؟ هل يبلغ أكثر قليلا من ثلاثة ملايين، كما يمكن استنتاجه من أخر تعداد للسكان؟ أم هل يرتفع عددهم إلى 5 أو 6 أو حتى 7 ملايين، كما تؤكد بعض الهيئات القبطية؟ إن التفاوت في التقدير أمر غريب في بلد تتوفر فيه الإحصاءات بغزارة، فمصر، على عكس بعض بلدان المنطقة لا تبخل بالمعلومات عن سكانا، إذ تجري التعداد بصفة منتظمة منذ سنة 1882م (أي في ظل الاحتلال الإنجليزي)، وغلبة الموظفين الأقباط في إدارات الإحصاء) وقد جاء (التعداد) بحصيلة لا بأس بها من المعلومات وهي حصيلة قابلة للتحقق منها ولمططابقة بينها وبين غيرها. ومع هذا فإن الجدل حول هذا الموضوع ما زال قائما، فالطائفة القبطية تقول أن تقرير عدد الأقباط بنسبة 6\% من عدد السكان الكلى، كما تشير إلى ذلك الإحصاءات الرسمية، فيه تقليل من عددهم ولكننا نلاحظ أن التعدادات التي أجريت في عهد الاستعمار تؤكد هذه الأرقام الرممية، ونلاحظ تناقصا طفيفا في نسبة عدد الأقباط كما يتبين من التعدادات المتتالية:

إذ كانت نسبة الأقباط أعلى قليلا من 8\% من العدد الكلي للسكان في مصر فيما بين عامي 1907، 1937م، ثم هبطت إلى 7.9\% في تعداد سنة 1947م والى 7.3\% في سنة 1960م (وبعد جلاء القوات الأجنبية وعدد كبير من الذين أصابتهم قوانين الإصلاح الزراعي وتصير الشركات)، و5.9\% في 1986م. وليس هناك أي استثناء في هذا المنحنى الهابط بانتظام، مما يوحي بأنه ليس هناك افتعال في هذه الظاهرة. إن أقباط مصر شأفم في ذلك شأن مسيحيي الشرق الآخرين، سبقوا المسلمين إلى تخفيض 
عدد المواليد، ولذلك قد هبطت نسبة عدد الأقباط بالنسبة للعدد الكلي من 7.3\% في سنة 1960م إلى

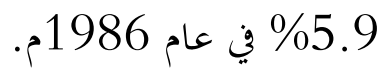

بهذا المنطق العلمي، وبالحقائق الإحصائية تناولت هذه المصادر -التي كتبها متخصصون غير مسلمين- حسم هذه القضايا التي دور حولها الجدل، وتثار بصددها الشكوك.

ويتوزع المسيحيون في البلاد العربية على عشرة طوائف رئيسية هي الأقباط الأرثوذوكس (ثلاثة ملايين)، والروم الأرثوذوكس (ثمانمائة ألف)، والكلدان (نصف مليون)، والروم الكاثوليك (أربعمائة ألف)، والأرمن الكرجيو (ثلاثمائة ألف)، واليعقوبيون (مائة وسبعون ألفا)، والسريان الكاثوليك (مائة وخمسون ألفا)، والأقباط الكاثوليك (مائة ألف)، والأرمن الكاثوليك (خمسة وسبعون ألفا) والنسطوريون (خمسون ألفا). ويتوزعون على البلاد العربية بنسبة متفاوتة أعلاها في لبنان (43.8\%) ثم في سوريا (6.4\%)، ومصر (5.7\%) والأردن (4.2\%)، وفلسطين (3.8\%). أما في كل من تونس والجزائر والمغرب وموريتانيا واليمن والصومال وليبيا فثمة نسبة قليلة تتراوح بين (1-2\%)، بينما تكون هذه النسبة في بقية البلدان العربية ضئيلة جدا.

وتبين موسوعة العالم الإسلامي نسبة غير المسلمين في الأقطار غير العربية المنتمية إلى منظمة المؤتمر الإسلامي * ويكن إجمال هذه النسب على الوجه الآتي:*

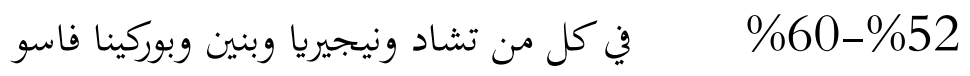

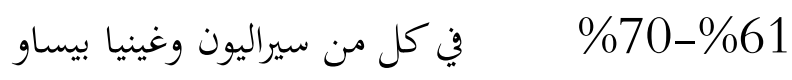

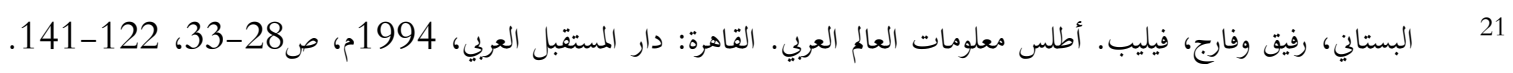

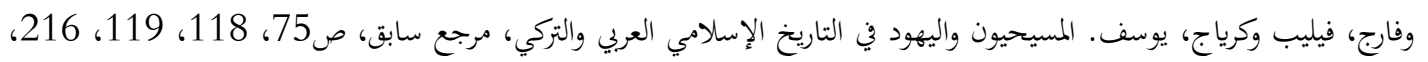

249، 284

أما أطلس معلومات العالم العربي فيشير إلى أن عدد اليهود يصل إلى ألفي نسمة في كل من تونس والجزائر وإلى حوالي ثمانية آلاف نسمة

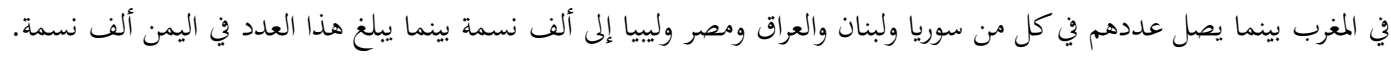

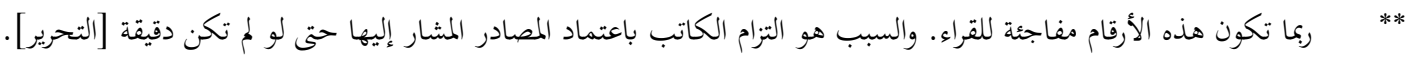




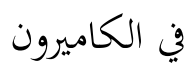

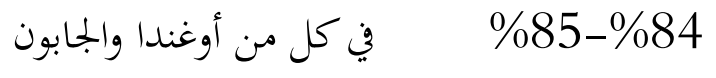

$$
\begin{aligned}
& \text { في غينيا } \\
& \% 31
\end{aligned}
$$

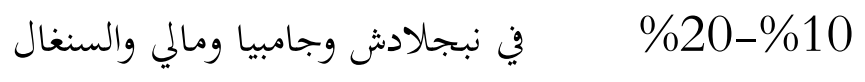

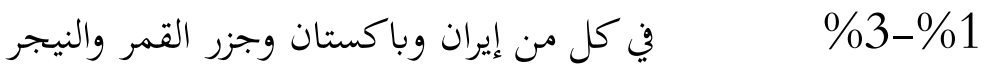

هذا عن التعداد المعاصر للأقليات غير المسلمة في الوطن العربي وبقية دول منظمة المؤتمر الإسلامي.

أما عن التحديات التي تواجه هذه الأقليات في واقعنا الراهن فإها في الحقيقة هي التحديات التي تواجه الأمة فقوى الهيمنة الغربية تريد أن بتعل من هذه الأقليات أوراق ضغط وثغرات اختراق وتدخل لإعاقة تقدم الأمة كل الأمة وغوضها وانعتاقها وانبعاثها الحضاري. إنها التحديات التي تعيد، مرة أخرى، قصة الغواية الاستعمارية، ومشاريع "الحماية" التي حاولتها قوى الغزو والاستعمار مع هذه الأقليات تاريخيا، تحاولها الآن قوى الهيمنة الغربية وفي المقدمة منها "العولمة الأمريكية"، ولذلك من خلال المخططات الاستعمارية المعلنة لتفتيت الأمة -أكثر مما هي مفتتة- وتحويل كياناتها القطرية إلى "كيانات ورقية وفسيفسائية" بواسطة الأقليات الدينية والمذهبية والقومية.

وهناك حقيقة يلمسها الدارس لمراحل وألوان هذه المخططات الاستعمارية الحديثة والمعاصرة للعب بأوراق الأقليات في وطن العروبة وعالم الإسلام، هي وجود الأصابع الصهيونية في كل هذه المخططات والمحاولات. فمنذ بدايات الغزوة الغربية الاستعمارية الحديثة للوطن العربي، قلب العالم الإسلامي، بواسطة حملة

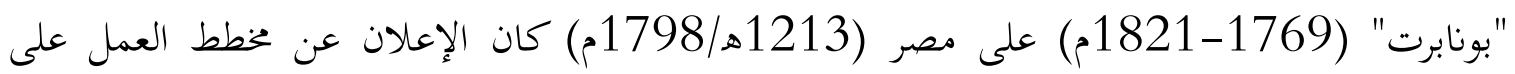
استخدام الأقليات في مشروع الهيمنة الاستعمارية على بلادنا، وذلك عندما أعلن "بونابرت" وهو في الطريق البحري من "مرسيليا" إلى "الإسكندرية" عزمه على بتنيد عشرين ألفا من أبناء الأقليات غير المسلمة، ليكونوا 
مواطئ أقدام وثغرات اختراق تعينه على بناء إمبراطوريته الاستعمارية الشرقية وأثناء حصاره لمدينة "عكا" الفلسطينية سنة 1799م -في الذكرى السبعمائة لاحتلال الصليبيين للقدس سنة 1097م- أصدر "بونابرت" نداءه إلى الأقليات اليهودية في العالم كي تتحالف معه لتحقيق هذا الغرض الاستعماري مقابل أن يساعدها على احتلال فلسطين. 22

ومنذ ذلك التاريخ، اتخذت قطاعات من هذه الأقليات اليهودية أكثر القرارات لا أخلاقية، وذلك عندما وظفت نفسها في خدمة الحضارة الغربية التي اضطهدت اليهود طوال تاريخهم، ضد الحضارة الإسلامية التي آوقم وأكرمتهم طوال تاريخها! فبدأت "الشراكة" بين الصهيونية وبين الاستعمار الغربي منذ ذلك التاريخ. الصهيونية تحلم بالخلاص من اضطهاد الغرب لليهود، على حساب العرب والمسلمين! والغرب الاستعماري يريد تحقيق "حزمة" من الأهداف، فهو يريد الخلاص من اليهود، الذين كان ينظر إليهم باعتبارهم سرطنات في جسم حضارته المسيحية، وذلك بقذفهم إلى قلب الوطن العربي، يقيم بواسطتهم قاعدة لحضارته، وآلة حربية ضد أحلام العرب في التقدم والنهوض. والبروتستانتية الغربية قد رأت في هذا المشروع الصهيونيالاستعماري تحقيقا لنبوءة أسطورية تتحدث عن عودة السيد المسيح، عليه السلام، ثانية ليحكم العالم ألف

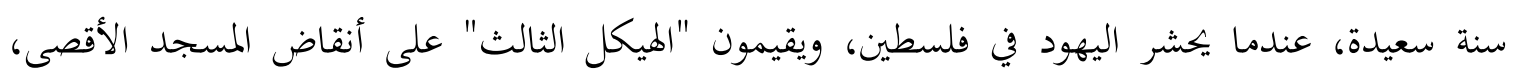
وتحدث معركة "هربجدون" التي يباد فيها المسلمون!23

وعندما هزم المصريون حملة "بونابرت" وتبددت أحلامه، وأصبحت القيادة -في المشروع الاستعماري الغربي- لإنجلترا، نقل الصهاينة "قبلتهم وشراكتهم" إلى الاستعمار الإنجليزي، وتولت إنجلترا رعاية هذه "الشراكة" وتوظيف الأقليات اليهودية ضد العرب والمسلمين.

وفي مواجهة مشروع "مصر - محمد على باشا" (1184-1265ه/1771-1849م) لتجديد شباب الشرق، وإنقاذه من الضعف العثماني للحيلولة دون نجاح خخططات الاستعمار الغربي سعت إنجلترا إلى

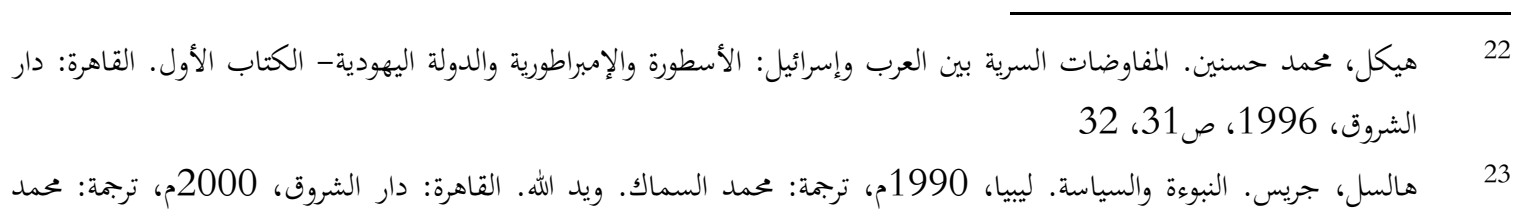
السماك. 
الدولة العثمانية كي تسمح بزرع اليهود في فلسطين، لإعاقة المشروع النهضوي لمحمد علي باشا، وطلب "بلمرستون" (1784-1865م) وزير خارجية إنجلترا سنة 1840م من سفيره في "الأستانة" أن يقنع السلطان العثماني بالسماح بهجرة اليهود إلى فلسطين "حتى يكونوا حجر عثره أمام محمد علي باشا ونواياه

$$
\text { والأغراض التي قد تخطر بباله أو بال من يخلفه!"24 }
$$

ولم تخرج فرنسا الاستعمارية من الساحة غهائيا بززيمة نابليون. فهي قد تولت تحويل الأقلية المارونية في لبنان -بواسطة التغريب الثقافي ومدارس الإرساليات التبشيرية- إلى ثغرات اختراق لتحويل قبلة هذه الأقلية وغيرها إلى الغرب، بدلا من الشرق والعروبة وحضارة الإسلام. وذلك وصولا إلى "جعل البربرية العربية" (كما قالوا) تنحني لا إراديا أمام الحضارة المسيحية لأوروبا. 25 كما تولت فرنسا -في المغرب العربي- اللعب بورقة الأقلية الإمازيغية لإلحاق عاداتما وأعرافها بالقانون الوضعي الفرنسي، بدلا من الشريعة الإسلامية وإلحاقها -لغويا وثقافيا- بالفرنسية والفرنكفونية، بدلا من هويتها الحضارية العربية الإسلامية.

ولقد كانت "الشراكة" الاستعمارية الصهيونية، والأصابع اليهودية حاضرة وفاعلة، دائما وأبدا في كل هذه المراحل لتنفيذ هذا المخطط الاستعماري للعب بأوراق الأقليات في بلادنا العربية والإسلامية. ولقد زاد من وضوح الدور الصهيوني في هذا المخطط وهذه التحديات منذ أن تجسد الحلم الصهيوني في الكيان الإسرائيلي سنة 1948، فرأينا الكتابات الصهيونية تضع مخططات تفتيت الشرق العربي والإسلامي، بواسطة الأقليات الدينية والمذهبية والقومية، باعتبار هذا التفتيت هو التعميم لمشروع الأقلية اليهودية في إقامة كياها السياسي الخاص. وباعتبار أن هذا التفتيت هو الضمان لأمن الكيان الصهيوني، الذي لا بقاء له ولا مستقبل في ظل الوحدة العربية والجامعة الإسلامية. لقد تصاعد إغراء الأقليات باختيار الطريق الصهيوني: عض اليد العربية الإسلامية والتوجه غربا، ضد العروبة والإسلام، وربط مستقبل هذه الأقليات بالهيمنة

$$
\text { الاستعمارية الغربية، بدلا من المشروع النهضوي للعرب والمسلمين! }
$$

$$
\begin{aligned}
& 24
\end{aligned}
$$

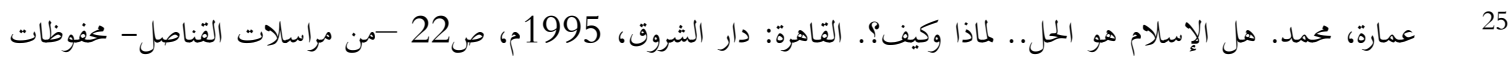

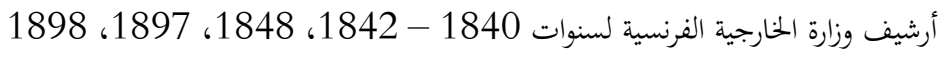


ومنذ أكثر من نصف قرن، وبالتواكب مع إقامة الكيان الصهيوني على أرض فلسطين -قاعدة عنصرية استعمارية غربية- لإعاقة تقدم أمتنا ووحدقا، أعلن المستشرق الصهيوني "برنارد لويس" Bernard Lewis البنتاجون Executive intelligence research projection وفيه يدعو إلى إضافة أكثر من ثلاثين كيانا انفصاليا على أساس ديني ومذهبي وعرقي (إثني)، تضاف إلى التجزئة التي أحدثنها اتفاقية (سيكس-بيكو) سنة 1916م. وبنص عبارة هذا المستشرق الصهيوني "فإن الصورة الجغرافية الحالية للمنطقة لا تعكس حقيقة الصراع، فما هو على السطح يتناقض مع ما هو في العمق. على السطح كيانات سياسية لدول مستقلة، ولكن في العمق هناك أقليات لا تعتبر نفسها ممثلة في هذه الدول، بل ولا تعتبر أن هذه الدول تعبر عن الحد الأدنى من تطلعاها الخاصة." وبعد أن تحدث عن تفاصيل مخطط تفتيت العالم الإسلامي -من باكستان إلى المغرب- على أسس دينية ومذهبية وعرقية، خلص إلى الهدف الصهيوني من وراء هذا التفتيت، فقال: ".. ويرى الإسرائيليون أن جميع هذه الكيانات لن تكون فقط غير قادرة على أن تتحد، بل سوف تشلها خلافات لا انتهاء لها. ونظرا لأن كل كيان من هذه الكيانات سيكون أضعف من إسرائيل، فإن هذه ستضمن تفوقها لمدة نصف قرن

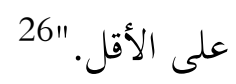

فالمطلوب هو استخدام الأقليات لتفتيت العالم الإسلامي إلى كيانات ضعيفة، لضمان الأمن والتفوق للكيان الصهيوني، الموظف في خدمة المشروع الإمبريالي الغربي الكبير. ولقد تحول هذا التخطيط "الاستعماري-الصهيوني" إلى الممارسة والتطبيق على أيدي "ديفيد بن جوريون" (1886-1973) و "موشى شاريت" (1894-1965م) و"موشى ديان" في حقبة خمسينيات القرن العشرين ابتداء بالأقلية المارونية في لبنان، وطموحا إلى تعميمه خارج لبنان... وكتب "شاريت" في مذكراته، عن المقاصد من وراء اللعب بأوراق الأقليات في بلادنا، يقول: إنا: أولا تثبيت وتقوية الميول الانعزالية للأقليات في العالم العربي؛ وثانيا إذكاء النار في مشاعر الأقليات المسيحية في المنطقة وتوجيهها نحو 
المطالبة بالاستقلال والتحرر من الاضطهاد الإسلامي! فمجرد تحريك الأقليات هو عمل إيجابي، لما قد ينتج

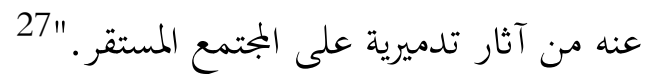

وفي مرحلة ثمانينيات القرن العشرين، ورغم الحديث عن "السلام، والتسوية، وتطبيع العلاقات"، بعد المعاهدة المصرية-الإسرائيلية سنة 1979م نجد أن هذا المخطط التفتيتي لعالمنا الإسلامي، بواسطة الأقليات هو من "الثوابت" الاستعمارية الصهيونية، التي لا تتأثر "بالمتغيرات" حتى ولو سميت هذه المتغيرات "بالسلام وتطبيع العلاقات."

ففي المحاضرة التي ألقاها "أرئيل شارون" -وكان يومئذ وزيرا للدفاع- في 18 ديسمبر سنة 1981م والتي نشرتا بجلة "معاريف" نراه يقول: "إن إسرائيل تصل بمجالها الحيوي إلى أطراف الاتحاد السوفيتي شمالا، والصين شرقا وإفريقيا الوسطى جنوبا، والمغرب العربي غربا "وهذا المجال الحيوي عبارة عن مجموعات قومية وإثنية ومذهبية متناحرة."

ثم يواصل "شارون" الحديث عن مشروعات تفتيت العالم الإسلامي، بواسطة الأقليات على النحو الذي سبقه إليه "برنارد لويس" حتى يكون هذا العالم الإسلامي "جالا حيويا لإسرائيل."28

وفي ذات الحقبة - ثمانينيات القرن العشرين- تصوغ "المنظمة الصهيونية العالمية" هذا المشروع التفتيتي تحت عنوان "استراتيجية إسرائيل في الثمانينيات" وتنشره في مجلتها الفصلية "كيفونيم" Kivunim (الاتحاهات) - في عدد 14 فبراير سنة 1982م. وفي ثنايا هذا المخطط الاستراتيجي، تتحدث عن النجاحات التي حققتها إسرائيل في لبنان - إبان الحرب الأهلية اللبنانية (1975-1989م) بواسطة قطاع من الأقلية المارونية-المارونية السياسية- باعتباره النموذج الواجب التعميم مع كل الأقليات، فتقول "المنظمة الصهيونية العالمية": "إن تفتت لبنان بصورة مطلقة إلى خمس مقاطعات إقليمية هو سابقة للعالم العربي بأسره، بما في ذلك مصر وسوريا والعراق وشبه الجزيرة العربية. إن دولا مثل ليبيا والسودان والدول الأبعد منهما (في المغرب) لن تبقى على صورتا الحالية، بل ستقتفى أثر مصر في اهيارها وتفتتها، فمتى تفتتت مصر تفتت 
الباقون (!) إن رؤية دولة قبطية مسيحية في صعيد مصر، إلى جانب عدد من الدول ذات سلطة أقليةمصرية، لا سلطة مركزية كما هو الوضع الآن، هو مفتاح هذا التطور التاريخي، الذي أخرته معاهدة السلام، لكنه لا يبدو مستبعدا في المدى الطويل.

وإن تفتت سوريا والعراق لاحقا إلى مناطق ذات خصوصية إثنية ودينية، على غرار لبنان هو هدف من الدرجة الأولى بالنسبة لإسرائيل. ولأن العراق أقوى من سوريا، وقوته تشكل في المدى القصير خطرا على إسرائيل أكثر من أي خطر، فهو المرشح المضمون لتحقيق أهداف إسرائيل في التفتيت، فتفتيت العراق هو أكثر أهمية من تفتيت سوريا.

وشبه الجزيرة العربية بأسره، مرشح طبيعي للاغهيار، وأكثر اقترابا منه، بفعل ضغط داخلي وخارجي، وهذا أمر غير مستبعد في معظمه، خصوصا في السعودية.

والأردن هدف استراتيجي في المدى القصير. فليس هناك أي إمكان بأن يبقى الأردن قائما على صورته وبنيته الحاليتين في المدى الطويل، وينبغي أن تؤدي سياسة إسرائيل حربا أو سلما إلى تصفية الأردن

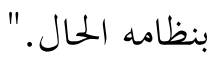

تم تخلص هذه الاستراتيجية -بعد التفصيل لمخطط التفتيت للعالم الإسلامي بواسطة الأقليات- إلى أن هذا هو "ضمان الأمن والسلام في المنطقة بأسرها في المدى الطويل. ففي العصر النووي لا يمكن ضمان بقاء إسرائيل إلا بمثل هذا التفكيك، ويجب من الآن فصاعدا بعثرة السكان، فهذا دافع استراتيجي، وإذا لم

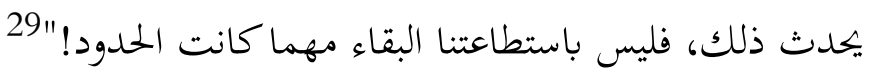

وفي حقبة التسعينيات -من القرن العشرين- تعود المؤسسات الصهيونية للتأكيد على "ثبات ثوابت هذه الاستراتيجية"، فيدعو "مركز باريلان للأبحاث الاستراتيجية" -التابع لجامعة باريلان الإسرائيلية- إلى ندوة عقدت في 20 مايو سنة 1992م، وشاركت فيها وزارة الحخارجية الإسرائيلية، بواسطة "مركز الأبحاث السياسية" التابع لها، وأسهم فيها باحثون من "مركز ديان"، التابع لجامعة "تل أبيب"، وذلك حول "الموقف

$$
29
$$


الإسرائيلي من الجماعات الإثنية والطائفية في منطقة الشرق الأوسط." وقد ناقشت هذه الندوة أحد عشر بحثا، دارت جميعها حول "تأييد إسرائيل للنزعات الانفصالية للجماعات العرقية والإثنية، والاعتبارات الكامنة

$$
\text { وراءه" وهذا هو عنوان أحد أبحاث هذه الندوة! }
$$

ولقد خلصت أبحاث ومقررات هذه الندوة إلى أن "هذه الأقليات هي شريكة لإسرائيل في المصير، ولابد من أن تقف مع إسرائيل في مواجهة ضغط الإسلام والقومية العربية، أو تبدي استعدادا لمحاربتها أو مقاومتها، وهي حليف وقوة لإسرائيل لتنفيذ سياسة الاستيطان والدولة التي مازالت في مرحلة التكوين!"30 وقد تزامن مع اشتعال الحرب الطائفية في لبنان - في سبعينيات القرن العشرين- غواية عدد من الشباب القبطي المصري بالاشتراك مع المارونية السياسية في هذه الحرب! واجتذبت الأصابع الصهيونية في أمريكا قطاعا من أقباط المهجر -وخاصة في أمريكا وكندا واستراليا- لتكوين "الهيئات القبطية" الداعية إلى ما تسميه "تحرير مصر القبطية من استعمار العروبة والإسلام!" حتى أفضت هذه الأنشطة الطائفية، المواكبة لهيمنة العولمة الأمريكية، والمدفوعة والمدعومة من "اللوبي الصهيوني"، ومنظمات وكنائس "التحالف المسيحي" و"المسيحية الصهيونية"، حتى أفضت إلى إصدار "الكونجرس الأمريكي" في أكتوبر سنة 1999 لقانون "الحريات الدينية الدولية"، الذي فرض الحماية الأمريكية على الأقليات الدينية -وخاصة في العالم الإسلاميوقنن لآليات إيقاع العقوبات الأمريكية على الدول التي لا ترضى عنها أمريكا في هذا المجال! وليس صدفة أن صدور هذا القانون قد جاء ثمرة لحملة إعلامية بدأها محام يهودي -هو "مايكل هوروفيتز "Michael Horowitz- في 5 يوليو سنة 1995م، ثم تلقفت الخيط المؤسسات والكنائس "المسيحية الصهيونية"، و"التحالف المسيحي" و"المحافظون الجدد" لتفضي هذه الحملة -الموجهة بالأساس إلى العالم الإسلامي- إلى قانون "الحماية والعقاب"، كما أسماه بحق الكاتب " سمير مرقص." 31

30 مندوة الموقف الإسرائيلي من الجماعات الاثنية والطائفية في العالم العربي. ترجمة: الدار العربية للدراسات والنشر، القاهرة: 1992م،

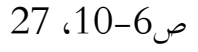
31 مرقص، سمير. الحماية والعقاب: الغرب والمسألة الدينية في الشرق الأوسط. القاهرة: ميريت للنشر، 2000م، ص151-156 
وليس صدفة كذلك، أن بتد هذه المخططات "مراكز أبحاث" ممولة من أمريكا والغرب، تركز على اللعب بورقة الأقليات في بلادنا، وتدعو إلى تطبيق ذات المخطط الذي دعا إليه "برنارد لويس" و"بن جوريون" و "موشى شاريت" و "موشى ديان" و"ارئيل شارون" و "المنظمة الصهيونية العالمية" خخط تفتيت العالم الإسلامي إلى كيانات سياسية -نعم سياسية- على أساس الدين والعرق والمذهب، أي تحويل التنوع من نعمة ومصدر قوة إلى نقمة وتشرذم وتفتيت. وتحويل الأقليات من لبنات في بناء الأمة والأمن الوطني والقومي والحضاري إلى ثغرات اختراق وأسباب للاهيار والدمار. فيكتب رئيس أحد أهم هذه "المراكز البحثية " يقول بالنص: "إن المجتمعات التي تتسم بالتعددية الإثنية في الوقت الحالي ينبغي أن تكون متعددة من الناحية السياسية أيضا!"32

ومع هذه الغواية الأجنبية، التي استجابت لها ووقعت في شباكها جمعيات وجماعات طائفية، تعيش في المهاجر، متعاونة مع الصهيونية وقوى الهيمنة الإمبريالية. وقلة قليلة من غلاة العلمانيين والطائفيين في الداخل، يستخدم المخطط الغربي -وخاصة الأمريكي- السلاح الاقتصادي في إذكاء الصراع الطائفي، فبواسطة المعونات الأمريكية الموجهة إلى القطاع الخاص، وتوكيلات الاستيراد والتصدير، والمعونات الموجهة للمشروعات التنموية الصغيرة، يتم التمييز الطائفي، لإيجاد واقع اجتماعي يمزقه "ثراء الأقلية" و"حرمان الأغلبية"!، لا حبا في سواد عيون الأقلية، وإنما لتأجيج الصراع الطبقي ذي الطابع الطائفي، تكرارا للتجربة التي سبق وصفها الاستعمار -ووآتت ثماتا في لبنان - إغناء الأقلية المارونية وإفقار الأكثرية المسلمة، وخاصة

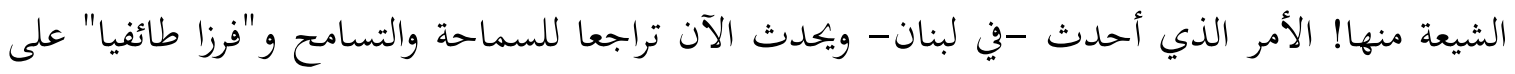
نهو غير معهود كما يخلق ضيقا بالآخر وتضييقا على بعض حقوقه الطبيعية المشروعة كالحال مثلا في موقف العامة والجمهور في بناء دور العبادة في بعض البلاد، بينما النهج الإسلامي يفتح الطريق أمام الحريات في هذه الميادين، حتى ليحض الدولة على إعانة غير المسلمين في بنائها.

وإذا كان هذا "التميز الاقتصادي" مما يعترف به العقلاء، حتى ليقول "الأنبا موسى" -أسقف الشباب في الكنيسة الأرثوذكسية المصرية- وهو من عقلاء وحكماء هذه الكنيسة "إن الأقباط جزء هام من نسيج 
الحياة المصرية. فهم أطباء وصيادلة ومهندسون، وغيرها من المهن، ونسبتهم في رجال الأعمال مرتفعة أكثر من نسبتهم العددية في مصر."33"

فإن هذه الفوارق الاقتصادية والاجتماعية المستفزة تشير إليها أرقام وإحصاءات رصدتا مصادر علمانية تقول: إن الأقلية النصرانية في مصر - والتي تقل نسبتها في السكان عن 6\%؛ والتي كان يصفها الشيخ محمد الغزالى (1335- 1416ه/1917-1996م) -عليه رحمة الله- بأها "أسعد أقلية في العالم" تملك من ثروة مصر ما بين 35\% و 40\%! فهي تملك وتمثل:

22.5\% من الشركات التي تأسست ما بين سنة 1974 وسنة 1995م -سنوات الانفتاح والمعونات الأمريكية، و20\% من شركات المقاولات في مصر، و50\% من المكاتب الاستشارية، و60\% من الصيدليات، و45\% من العيادات الطبية الخاصة، و35\% من عضوية غرفة التجارة الأمريكية وغرفة التجارة الألمانية، و60\% من عضوية غرفة التجارة الفرنسية (منتدى رجال الأعمال المصريين والفرنسيين)، و20\% من رجال الأعمال المصريين، و20\% من وظائف المديرين بقطاعات النشاط الاقتصادي بمصر، وأكثر من 20\% من المستثمرين بمدينتي السادات والعاشر من رمضان، 15.9\% من وظائف وزارة المالية المصرية، و25\% من المهن الممتازة والمتميزة -الصيادلة، والأطباء، والمهندسين، والبيطريين، والمحامين. 34 وذلك فضلا عن أن هذه الأقلية نادرا ما يعاني أحد منها من المشكلات التي تطحن سواد الأغلبية -

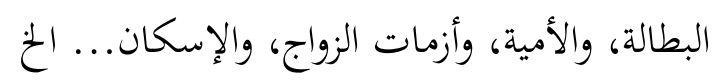

ومع كل ذلك تصدر القوانين الأمريكية لحماية "أسعد أقلية في العالم!" ويأتي أعضاء الكونجرس الأمريكي والدبلوماسيون الأمريكيون والغربيون "ليفتشوا" عن أحوالهم، ليرفعوا التقارير التي تتحدث عن "اضطهادهم!" وتطلب توقيع العقوبات على مصر وشعبها، وفق القانون الأمريكي، قانون "الحماية

$$
33
$$

34

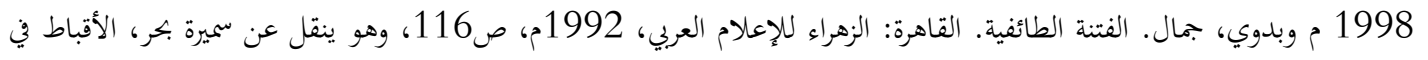

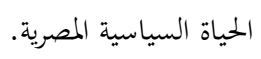


والعقاب!" وتصدر "الهيئات القبطية" في المهجر الكتب والنشرات داعية إلى تحرير هذه الأقلية من العروبة والإسلام!

هذا هو "الفعل الاستعماري في المسألة الطائفية" وتلك هي "ردود الأفعال" على هذه التحديات في تطبيقاةا على الأقلية القبطية في مصر . وهي أكبر الأقليات النصرانية العربية عددا وأهم "الأوراق" التي يحاول

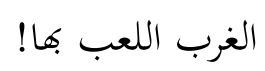

وإذا كنا نحذر من "الفعل الاستعماري" و"النزعة الطائفية الانعزالية"، التي تعمل على إحياء اللغة القبطية - كما أحيت الصهيونية العبرية-كي تحل محل اللغة العربية، التي هي اللغة الوطنية والقومية والحضارية للأمة كلها، على اختلاف أدياغا! فإننا ندعو إلى أن تتحمل الأغلبية مسئولياها الكبرى في مواجهة هذه التحديات، وفي قطع الطريق على خخطاتما. وذلك عن طريق:

1. حل المشكلات الحقيقية التي تعاني منها الأقليات، باعتبارها جزءا من الأمة، وباعتبار مشكلاتا

$$
\text { جزءا من مشكلات الأمة. }
$$

2. وإدارة حوار داخلي بين "الحكماء" لتحديد وتمييز "المظالم" الحقيقية من "الأحاسيس الزائفة أو

المثضخمة بالظلم!" فالحكماء في مختلف الفرقاء كثيرون، وهم الممثلون للأغلبية.. وحوارهم هو السبيل لقطع الطريق على القلة العميلة والمعادية، التي صنعها ويغذيها الاستعماريون والصهاينة. وقطع الطريق على الغلو الديني عند مختلف الأطراف.

3. وإعمال المنهاج الإسلامي في "مداواة الجراح"، بدلا من "توسيع هذه الجراح". فمن الخطأ والخطيئة

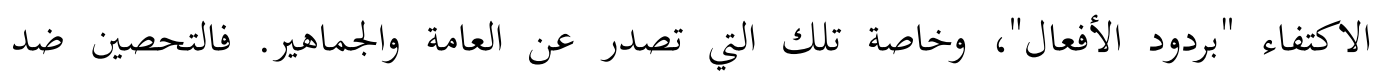
الغوايات، وإقالة العثرات هو الأولى بالاتباع، وليس تصيد الأخطاء.

وعلينا أن نتذكر ما صنعته الأمة -قبل قرنين من الزمان- عندما نجحت غواية الحملة الفرنسية على مصر في اجتذاب "المعلم يعقوب حنا" و"الفيلق القبطي" الذي قاده. فسقطوا في حظيرة الخيانة لأمتهم وطائفتهم وكنيستهم. فلقد صدر العفو -بعد هزيمة هذه الحملة سنة 1801م- عن الذين استجابوا لهذه 
الغواية، وصدرت "الفرمانات السلطانية" التي أعلنت هذا العفو، والتي تحذر من الانتقام، ومن فتنة لا تصيبن الذين ظلموا خاصة. ولقد تحدث "الجبرتي" عن هذا المنهاج في مداواة جراح تلك الغواية، فقال: لقد نودي بأن لا أحد يتعرض بالأذية لنصراني ولا يهودي، سواء كان قبطيا أو روميا أو شاميا، فإهم من رعايا السلطان والماضي لا يعاد. وكتبت فرمانات، وأرسلت إلى البلاد -في الأقاليم- مضموفا: الكف عن أذية النصارى واليهود وأهل الذمة، وعدم التعرض لهم، وفي ضمنها -أي الفرمانات- آيات قرآنية، وأحاديث نبوية، والاعتذار عنهم بأن الحامل على تداخلهم مع الفرنساوية: صيانة أعراضهم وأموالهم -كما قرئت فرمانات-

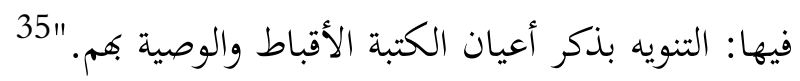

فالأقليات جزء أصيل من نسيج الأمة، لهم كل ما للأمة من الحقوق، وعليهم جميع ما عليها من الواجبات. ومسئولية الأغلبية في صد الغوايات، ومعالجة جراحاقا أكبر بكثير من مسئولية الأقليات.

هكذا بدأ، واستمر، ويتم اللعب بأوراق الأقليات الدينية والقومية -غير المسلمة- وأيضا المسلمة في وطن العروبة وعالم الإسلام. وهكذا يجب الوعي بمخاطر هذه التحديات التي تواجه وحدة الأمة وتقدمها.

\section{رابعا :نظرة إلى المستقبل}

وإذا كانت هذه هي التحديات التي تواجه الأقليات في واقعنا الراهن، ويواجه بها المشروع "الاستعماري الصهيوني" أمتنا، محاولا استخدام "أوراق" هذه الأقليات لتفتيت الأمة، فما هو الحل الذي نواجه به هذه التحديات؟

إننا إذا استثنينا "حل" التجزئة والتفتيت للأمة على أسس دينية ومذهبية وقومية؛ لأنه ليس "حلا" وإنما هو "المشكلة والتحدي"، فإن هناك مشروعين يتم الحديث عنهما لتحقيق التحصين لجسد الأمة ضد هذه التحديات: 
أولمما: الحل العلماني، الذي يبشر به العلمانيون، يتصور أصحابه أن "العلمانية" -التي تستبعد المرجعية الإسلامية من السياسة والدولة والقانون والدستور ومشروع النهضة- هي لحل لمشكلة الأقليات في بلادنا، كما مثلت -برأيهم - الحل لمذه المشكلة في النموذج الحديث والمعاصر للمجتمعات الغربية. وثانيهما: الحل الإسلامي، الذي بدأ به الإسلام التعامل مع "الآخر"، كل ألوان "الآخر" وقد حول الإسلام بهذا الحل هذا "الآخر" إلى جزء من "الذات"، ذات الدين الإلهي الواحد، في ظل المرجعية الإسلامية الواحدة. وهو النموذج والحل الذي تحدثنا عنه في القسم الثاني من هذه الدراسة. وكان له الفضل في إنقاذ أهل الديانات الأخرى من الإبادة، حتى لكأن وجودها وبقاءها في الشرق هو "هبة" هذا الحل الإسلامي. كما أنه هو الحل الذي عرفته الأمة، واندمج به "الآخرون" مع المسلمين في أمة واحدة، عبر هذا التاريخ الطويل. وملا كنا قد سبق وانتقدنا ورفضنا وفندنا "الحل العلماني" في عدد من كتبنا، 36 فإننا نكتفي في هذا المقام بالإشارة إلى أن العلمانية قد مثلت وتمثل المأزق وليس الحل لما يسمى بمشكلات الأقليات. فالعلمانية وافد غربي، يستبعد المرجعية الإسلامية، التي هي هوية الأمة، والتي تتمسك بها الأغلبية وقطاعات واسعة من الإقليات. 37 فاستبدال العلمانية بالمرجعية الإسلامية، هو -في الحقيقة- بمثابة فرض قطاع محدود من الأقلية -أي أقلية الأقلية! -رأيه على أغلبية الأمة! وتحويل هذه الشريحة إلى "فيتو" ضد أغلبية الأمة وهويتها وتاريخها! وفي هذا تعميق للشقاق على أسس طائفية، وتحقيق لمقاصد التحديات، وليس حلا نواجه به هذه التحديات، فضلا عن أنه نفي وإلغاء لجوهر الديمقراطية، التي يجتمع حولها ويتمسك بها الجميع، والتي تعطى الوزن المناسب لرأى الأغلبية في تحديد مقومات المجتمع، طالما أها لا تنتقص من عقائد الأقليات وحقوقها. وفوق كل ذلك، فإنه يبدو غريبا الدعوة إلى العلمانية -وهي وافد غربي- لحل مشكلة الأقليات، بعد أن

36 36

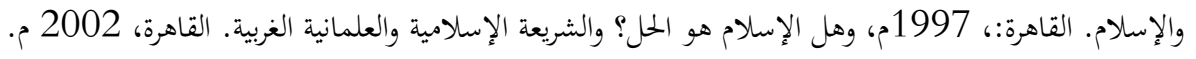

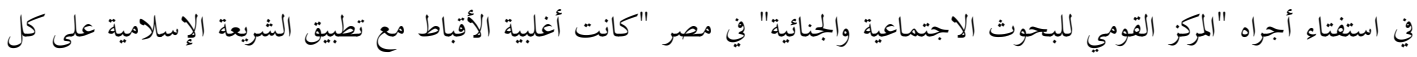

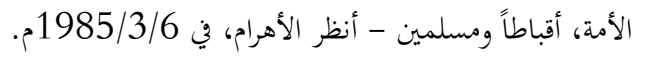


سقطت وأفلست كل الحلول الغربية الوافدة، التي أضاعت أمتنا قرنين من عمرها وهي تجرب النهوض وفق نماذجها! وإذا كان الحديث عن أقليات دينية، فإن المرجعية الإسلامية -التي عاشت في ظلالها هذه الأمة أربعة عشر قرنا، كانت في أغلبها "العالم الأول" على ظهر هذه الأرض- ليست بديلا لما تتدين به هذه الأقليات، حتى تكون تعديا على حريتها في الاعتقاد الديني، لأن هذه المرجعية الإسلامية تترك هذه الأقليات وما تتدين به، وتقتصر تطبيقاما على الجانب المدني والقانوي والسياسي، الذي ليس له مناظر في النصرانية - التي تدع ما لقيصر لقيصر، وتقف عند ما لله.

ففقه المعاملات الإسلامي هو اجتهادات بشرية، في ظل منظومة القيم الإيمانية، التي لا تختلف باختلاف الشرائع السماوية المتعددة، والاجتهادات فيه مفتوحة أبوابها لكل أصحاب العطاء القانوني، على اختلاف الديانات التي يتدينون بها. فكما جعل الإسلام شريعة من قبلنا شريعة لنا ما لم ينسخها التطور التاريخي، فتح الباب أيضا أمام كل أبناء الأمة، على اختلاف مللهم ونحلهم، للإسهام في البناء لحضارة الإسلام. ومن ثم فهو يفتح كل الأبواب أمام كل عقول الأمة للإسهام في بلورة المشروع النهضوي المتميز لهذه الأمة -الأقليات منها والأغلبيات - ومن هنا تصبح المرجعية الإسلامية، فيما وراء ما جاءت به النصرانية من عقائد، حلولا "وطنية، وقومية، وحضارية" لكل أبناء الأمة، بتمعتهم على هوية حضارية واحدة، ومشروع هضوي واحد، فيصبح فوضهم المعاصر المنشود امتدادا لتاريخهم في النهوض والازدهار الحضاري، ويصبح فقه "الشافعي" (150-204ه/767-820م) فقها وطنيا بالنسبة لكل المصريين لا يمكن أن يتقدم عليه فقه نابليون، الذي جاء غازيا قاهرا لكل المصريين. وكذلك الحال مع فقه "أبي حنيفة" (80150هـ699-767م) في العراق، وفقه الإمام مالك (93-179هـ/712-795م) في أقطار المغرب العربي. إن وطنية النصراني الشرقي لا يمكن أن تفضل القانون الروماني، قانون "جستنيان" الذي اضطهد النصرانية الشرقية، على فقه "الليث بن سعد" (94-175هـ/713-791م) الذي أفتى بأن بناء الكنائس 
وأكثر من هذا، فلقد مثلت العلمانية -عندما طبقت في تركيا، بعد إسقاط الخلافة الإسلامية سنة 1924م- نكبة على الأقليات الدينية والقومية، ولم تكن حلا لمشكلاقها بأي حال من الأحوال، ويكفى أن نعلم أن نسبة النصارى في سكان الخلافة العثمانية سنة 1550 قد كانت 41.8\%، وأها ظلت حتى بعد انفصال واستقلال بلاد البلقان واستقلالما تمثل 19.1\% من السكان سنة 1914م. فلما جاءت العلمانية أجهزت على هذه الأقلية النصرانية، فلم يبق منها في سنة 1991م سوى 0.2\% من السكان!38 وحتى الاضطهاد، وما يقال عن "الإبادة" التي حدثت للأرمن سنة 1915م فإن مرتكبيها هم العلمانيون من قادة "الاتحاد والترقي"، الذين انقلبوا على المرجعية الإسلامية للخلافة العثمانية.

أما حال الأكراد، في ظل هذه العلمانية التركية -التي يريدونا حلا لمشكلات الأقليات- فهو لا يقل سوءا -رغم إسلامهم- عن حال النصارى، فهم محرومون من الحديث بلغتهم، فضلا عن التعليم والكتابة بها! بل ومحرومون من أن يسموا أبناءهم وبناقم بالأسماء التي يريدون!

إن الأقليات -غير المسلمة وكذلك المسلمة- قد عاشت وتعايشت وآمنت وازدهرت في ظل المرجعية الإسلامية، في ظل شريعة "لهم مالنا وعليهم ما علينا"، ولم تُعرف المشكلات إلا في ظل الاستعمار وغواياته، وفي ظل العلمانية التي جلبها إلينا هذا الاستعمار، وصدق "الأنبا موسى" عندما قال عن حال أقباط مصر

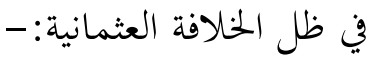

"... حينما نذكر الأقباط أيام الدولة العثمانية، كانوا مع إخواهم المصريين لهم دور مشترك.. وكثير من

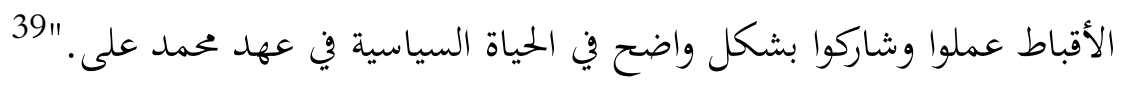
بل إن هذه العلمانية، ذات النشأة الأوروبية، قد تحولت إلى "مأزق أوروبي" همش المسيحية في أوروبا، وجعل مجتمعاتما فراغا دينيا، انصرف فيه أغلبية الناس عن الإيمان الديني، حتى لتغلق الكنائس وتباع! ثم عجزت هذه العلمانية عن أن تملأ هذا الفراغ، وتجيب على أسئلة النفس الإنسانية التي يجيب عنها الدين. وبشهادة القس الألماني -عالم الاجتماع- الدكتور "جوتفرايد كونزلن": "... فلقد نبعت العلمانية من التنوير

$$
\begin{aligned}
& 38
\end{aligned}
$$

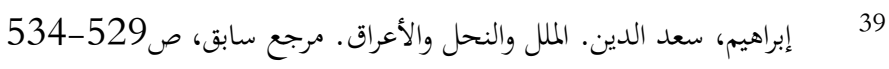


الغربي، وجاءت ثمرة لصراع العقل مع الدين، وانتصاره عليه، باعتباره مجرد أثر لحقبة من حقب التاريخ البشري، يتلاشى باطراد في مسار التطور الإنساني، ومن نتائج العلمانية. فقدان المسيحية لأهميتها فقدانا كاملا، وزوال أهمية الدين كسلطة عامة لإضفاء الشرعية على القانون والنظام والسياسة والتربية والتعليم، بل وزوال أهميته أيضا كقوة موجهة فيما يتعلق بأسلوب الحياة الخاص للسواد الأعظم من الناس، وللحياة بشكل عام، فسلطة الدولة وليست الحقيقة هي التي تصنع القانون، وهي التي تمنح الحرية الدينية."

ولقد قدمت العلمانية الحداثة باعتبارها دينا حل محل الدين المسيحي، يفهم الوجود بقوى دنيوية هي العقل والعلم. لكن وبعد تلاشى المسيحية في أوروبا، سرعان ما عجزت العلمانية عن الإجابة على أسئلة الإنسان، التي كان الدين يقدم لها الإجابات. فالقناعات العقلية أصبحت مفتقرة إلى اليقين. وغدت الحداثة العلمانية غير واثقة من نفسها، بل وتفككت أنساقها -العقلية والعلمية- عدمية ما بعد الحداثة. فدخلت الثقافة العلمانية في أزمة، بعد أن أدخلت الدين المسيحي في أزمة، فالإنماك الذي أصاب المسيحية أعقبه إعياء أصاب كل العصر العلماني الحديث. وتحققت نبوءة "نيتشه" (1844-1900م) عن "إفراز التطور الثقافي الغربي لأناس يفقدون (نجمهم) الذي فوقهم ويحيون حياة تافهة، ذات بعد واحد لا يعرف الواحد منها شيئا خارج نطاقه" وبعبارة "ماكس فيبر" (1864-1920م) "لقد أصبح هناك أخصائيون لا روح هم، وعلماء لا قلوب لهم!" لقد أزالت العلمانية السيادة الثقافية للمسيحية عن أوروبا. ثم عجزت عن تحقيق سيادة دينها العلماني على الإنسان الأوروبي، عندما أصبح معبدها العلمي عتيقا! ففقد الناس "النجم" الذي كانوا به يهتدون."40 هكذا تحدث "قس وعالم اجتماع" عن تحول العلمانية - في بلاد نشأقا- إلى مأزق، عندما هزمت الدين الإلهي ثم لحقت الهزيمة "بدينها الطبيعي"، ففقد الناس "النجم الذي به يهتدون!" فهل يريد العلمانيون -بسبب الأقليات الدينية- أن ندخل في هذا الطريق، وهذا المأزق الذي دخل فيه الغربيون؟! وألا تفيق النصرانية في بلادنا، فتعلن رفضها لكأس السم الذي تجرعته النصرانية الأوروبية، كونزلن، جوتفرايد. مأزق المسيحية والعلمانية في أوربا. تقديم حممد عمارة، القاهرة: غضضة مصر، 1999م، ص28، 31، 32، 36، 
وتدرك أن منظومة القيم الإيمانية -التي تتفق فيها كل الأديان- لابد أن تكون لها السيادة في حياتنا، وأن الشريعة الإسلامية هي أرعى للنصرانية والنصارى من العلمانية والعلمانيين؟! وفي هذا الإطار، علينا أن نذكر ونذكر بالكلمات العاقلة والحكيمة التي رأت وترى "جوامع الإسلام" - في الشريعة والحضارة- باعتبارها "جوامع الأمة" وليست "خصوصية" للمؤمنين بالإسلام، دون الآخرين أن نتذكر: كلمات البابا "شنودة الثالث" بطريرك الكنيسة الأرثوذكسة، التي قال فيها: "إن الأقباط في ظل حكم الشريعة الإسلامية، يكونون أسعد حالا وأكثر أمنا، ولقد كانوا في الماضي حينما كان حكم الشريعة هو السائد. فنحن نتوق إلى أن نعيش في ظل "لمم ما لنا وعليهم ما علينا"، مصر بتلب القوانين من الخارج حتى الآن، وتطبقها علينا. ونحن ليس عندنا ما في الإسلام من قوانين مفصلة، فكيف نرضى بالقوانين المجلوبة، ولا نرضى بقوانين الإسلام؟" 41

ولقد رحب البابا "شنودة" أخيرا بالحلول الإسلامية التي يقدمها الفقه الإسلامي لمشكلات الأسرة المسيحية -ومنها قانون "الخلع"- وقال، رغم معارضات متعصبة ترفض "الخلع" لا لشيء إلا لمصدره الإسلامي: - "إن الخلع مبدأ موجود منذ القديم في الشريعة الإسلامية، ولم يكن عديد من الناس على معرفة به. وبمقتضى مبدأ الخلع من حق المرأة أن تطلب الانفصال عن زوجها لأسباب بينتها للمحكمة، منها استحالة الحياة الزوجية بينهما. وإذا كان قانون الخلع يسمح للمرأة المسلمة بأن تستفيد من هذا الوضع، فما المانع من أن تستفيد منه المرأة المسيحية؟

فالمعروف في القانون هو عمومية القانون، فلا نطبقه في حالة معينة لفائدة "البعض ونرفضه في حالة أخرى لفائدة البعض الآخر. إذن، الخلع يسمح للمرأة، مسيحية كانت أو مسلمة، أن تتخلص من الزوج

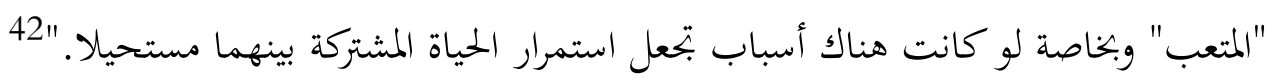

فالوحدة الوطنية من مقوماتحا -بعد وحدة منظومة القيم، ووحدة المدرسة- وحدة المحكمة، ووحدة القانون، طالما لم يكن هناك نص ديني قطعي وجلي مخالف للشريعة العامة، الشريعة الإسلامية. ففيما يتعلق 
بمثل هذا النص يترك غير المسلمين وما يدينون. أما في فقه المعاملات -ومنه أغلب قوانين الأحوال الشخصية وكل القوانين المدنية والجنائية والتجارية والدولية- فالفقه الإسلامي فيها قانون مدني عام لكل الأمة، على بلى بلى

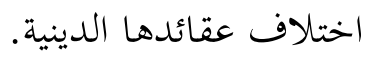

كذلك علينا أن نتذكر كلمات القائد الوطني "مكرم عبيد باشا" (1307-1380هـ/18891961م) التي يقول فيها: "نخن مسلمون وطنا ونصارى دينا. اللهم اجعلنا نحن المسلمين لك، وللوطن

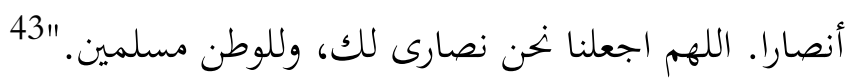

ولقد فصل هذه الحقيقة أبو القانون المدني الحديث، القاضي العادل، الدكتور "عبد الرزاق السنهوري باشا" (1313-1391-1895-1971م) عندما تحدث عن "جامع الإسلام، وشريعته، وفقه المعاملات فيه" باعتبارها مقومات الوحدة للأمة جمعاء فقال: "إن الإسلام دين ومدنية. والمدنية الإسلامية لا تعني مجتمعا من المسلمين فقط، وإنما تعني مجتمعا ذا طابع فذ من المدنية قدمها لنا التاريخ كثمرة للعمل المشترك، ساهمت فيه جميع الطوائف الدينية" التي عاشت وعملت معا جنبا إلى جنب تحت راية الإسلام، والتي قدمت لنا بذلك تراثا مشتركا لجميع سكان الشرق الإسلامي. إن المدنية الإسلامية هي ميراث حلال للمسلمين والمسيحيين واليهود من المقيمين في الشرق، فتاريخ الجميع مشترك، والكل تضافروا على إيجاد هذه المدنية. والشريعة الإسلامية لا ينبغي الاقتصار على كوفا صالحة لتطبيقها على المسلمين وحدهم في العصر الحاضر، بل على غير المسلمين أيضا وذلك دون إرغام غير المسلمين على إتباع خلاف عقائدهم. ولذلك "يجب أن تكون حركة إحياء الشريعة الإسلامية مبنية على أساس لا يتناقض مع هذه المعتقدات، وأن يشترك في هذه الحركة الإحيائية إلى جانب المسلمين، غيرهم من الشرقيين غير المسلمين، القانونيين منهم والاجتماعيين، وأن نطبق قاعدة: أن الشريعة الإسلامية تكملها الشرائع الأخرى ما لم تتناقض معها هذه

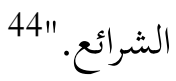

$$
43
$$

السنهوري، عبد الرزاق. الأوراق الشخصية. إعداد نادية السنهوري، توفيق الشاوي، القاهيات العادة: الزهراء للإعلام العربي، 1988م، في

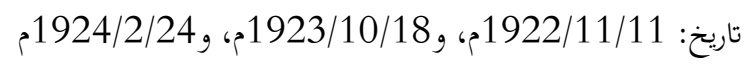


فالعلمانية ليست الحل، بل إها هي المأزق الذي يشكو منه عقلاء الأوروبيين والغربيين الذين شربوا كأسها المسموم. وحرام أن يظل العلمانيون في بلادنا مثل أهل الكهف؛ يشرون "بالحداثة الغربية" بعد أن تجاوزها أصحاهما إلى عدمية وتفكيك "ما بعد الحداثة"! ويدعون إلى العلمانية، بعد أن أفلست في المجتمعات التي نشأت فيها، وشهد العالم ويشهد صحوات دينية حتى عند أهل الديانات الوضعية، ورأينا ونرى "اللغة الدينية" و"المقاصد الدينية" تسود حتى في ميادين السياسة بالبلاد التي ظننا أها علمانية حتى النخاع!

إذن، يجب أن نتوجه جميعا إلى الشرق وأن نحذر ونتخلص من غوايات الغرب، وأن نخلص الولاء والانتماء لمقومات حضارتنا الواحدة الجامعة، الحضارة الإسلامية التي ورثت واستوعبت وأحيت كل المواريث الحضارية التي سبقت ظهور الإسلام، والتي شاركت في بنائها كل شعوب الشرق، على اختلاف عقائدها الدينية، فالتغريب، والغوايات الغربية، والاختراق الغربي لأمن أمتنا، الوطني والقومي والحضاري، هي المخاطر المحدقة بوحدتنا الوطنية والقومية والحضارية.

ولنتذكر كلمات شهيد الحرية عبد الرمن الكواكبي (1270- 1320ه//1854- 1902م)، قبل قرن من الزمان: "يا قوم، أليس مطلق العربي، أخف استحقارا لأخيه من الغربي؟ هذا الغربي قد أصبح ماديا لا دين له غير الكسب، فما تظاهره مع بعضنا بالإخاء الديني إلا مخادعة وكذبا. فالذين يطاردون الدين

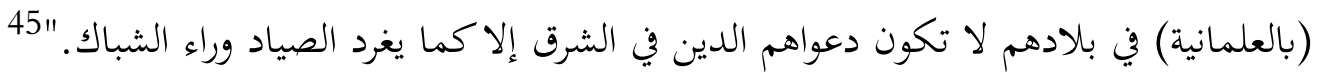

فنحن جميعا شرقيون، حضارة ومدنية وقيما. وبعبارة "السنهوري باشا": "..فالشرق بالإسلام" والإسلام بالشرق، وإغما لشيء واحد، وأمتنا ذات مدنية أصيلة، وهي أكثر تَذيبا من المدنية الأوروبية، وليست هي الأمة الطفيلية التي ترقع لمدنيتها ثوبا من فضلات الأقمشة التي يلقيها الخياطون. "46 وإذا كان أسلافنا قد علمونا أن صلاح آخر هذه الأمة لن يكون إلا بما صلح به أوها، فإن المنهاج الإسلامي الذي جعل "الآخر" جزءا من "الذات" ذات الأمة، والرعية، والدولة والقومية والحضارة بل والدين 
الإلهي الواحد، مع الاختلاف في الشرائع، هو أصلح المناهج لبناء الوحدة الوطنية والقومية والحضارية لشعوب الأمة الإسلامية، هذه الوحدة التي نواجه بما مختلف الغوايات وجميع التحديات.

وعلينا أن نتذكر -كمنطلق لنا في هذا المقام- كلمات رسول الإسلام، ورحمة الله للعالمين، وخاتم

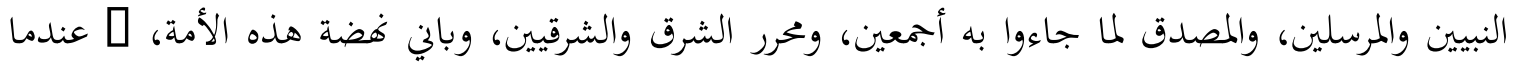
أعطى العهد والميثاق لغير المسلمين أن يكونوا (مع المسلمين أمة واحدة بينهم النصر والنصح والنصيحة والأسوة والبر دون الإثم، لهم ما للمسلمين وعليهم ما على المسلمين، وعلى المسلمين ما عليهم، حتى يكونوا شركاء فيما لهم وفيما عليهم، وأن أحرس دينهم وملتهم بما أحفظ به نفسي وخاصتي وأهل الإسلام من ملتي." ذلك هو دستور العدل والإنصاف لوحدة الأمة، مع كل الحقوق والحريات في التنوع الديني، في ظل الولاء والانتماء لحضارتنا المشتركة الواحدة، حضارة الإسلام.

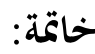

في ختام هذه الدراسة نجيز لأنفسنا أن نرشح "لجماعة الحكماء"، التي يجب أن تأتلف لتدير الحوار الموضوعي حول مشكلات الأقليات، والتحديات التي تواجه الأمة بسبب استغلال الغرب الاستعماري لهذه المشكلات؛ أقول نرشح هذه "النقاط الساخنة" والتي يجب أن تتصدر "جدول أعمال" هذا الحوار، فإننا نرشح ضرورة استبعاد الأوهام التي تروجها قطاعات أقباط المهجر، تلك التي سقطت في شباك الغواية الصهيونية الغربية، والتي تزعم أن العروبة والإسلام طارئين على الشرق، ويجب "تحرير" النصرانية الشرقية منهما! فليست هناك -ولا يعقل أن تكون- "امتيازات للأقدمية الدينية". فدين الله واحد، والتعددية والتوالي إنما هما في الشرائع والنبوات والرسالات، التي هي معالم على طريق الوصول إلى الله. فالمسلمون الفرس هم إيرانيون زرادشتيون أسلموا وليسوا طارئين ولا وافدين على إيران، وكذلك المسلمون المصريون، هم مصريونأي أقباط- أسلموا، وليسوا مهاجرين من شبه الجزيرة العربية إلى مصر. وعلى الذين يزعمون أن المسلمين في المشرق والمغرب هم مهاجرون طارئون على البلاد التي فتحها المسلمون، أن يتعلموا ويعلموا حقائق "الديموجرافيا"، التي كتبها ونشرها العلماء غير المسلمين، والتي تقول: إن كل سكان شبه الجزيرة العربية في 
عهد الخلافة الراشدة، أي عصر الفتوحات كان عددهم مليون نسمة فقط. بينما كان عدد سكان مصر والشام والعراق وفارس وحدها أي باستثناء المغرب تسعة وعشرين مليون نسمة. 47 فحتى لو هاجر كل سكان شبه الجزيرة العربية -وهذا لم يحدث- إلى البلاد التي فتحها المسلمون لما كان لذلك أي أثر "ديموجرافي" على التركيبة السكانية الأصلية لتلك البلاد.

وإذا كانت قد تمت هجرات عربية مسلمة محدودة العدد إلى تلك البلاد، فلقد تمت إليها هجرات

$$
\text { أرمنية ويونانية وقبرصية مسيحية أيضا. }
$$

وعلى الذين يقولون إن الإسلام "وافد" على النصرانية في تلك البلاد، أن يتذكروا أن النصرانية "وافدة" على تلك البلاد أيضا، بل هي وافدة، حتى على الفاتيكان! كما أن اليهودية "وافدة" على كل البلاد التي دخلتها، بما في ذلك فلسطين! وإذا كانت "الأقدمية الدينية" ميزة وامتيازا فلربما كان الفوز بهذا الامتياز هو للذين يعبدون "العجل أبيس!" فعلينا أن نبدأ حوار الحكماء بتبديد هذه الأوهام. إن المساواة في حقوق المواطنة السياسة والاجتماعية والاقتصادية هي حق إلهي بحكم خلق الله، سبحانه وتعالى، للإنسان، من الأقليات أو من الأغلبيات كان هذا الإنسان؛ فهذه المساواة ليست بجرد حق من حقوق الإنسان، تُمنح أو تُمنع تبعا لدرجة التسامح في المجتمع والدولة، وإنما هي "حق إلهي" بحكم الخلق والتكريم الإلهي لمطلق الإنسان.

وإذا كان الحق في بناء دور العبادة، وفي إقامة الشرائع الدينية فيها، هو مما كفله الإسلام، بل وأوصى الدولة الإسلامية بأن تعين وتساعد عليه غير المسلمين، قرر الإسلام ذلك، وطبقه قبل أي حديث عن حقوق الإنسان. ولما كانت هذه القضية قد اكتسبت الكثير من الحساسية، لكثرة ما قيل فيها وعنها، ولما

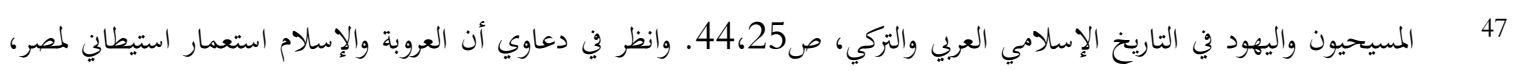

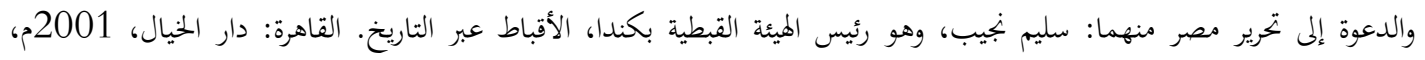

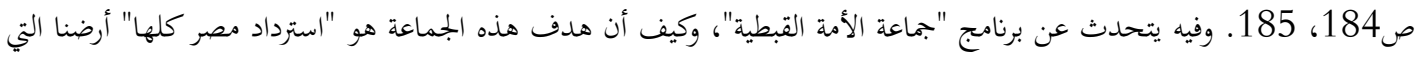

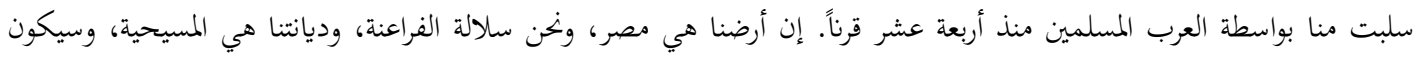


اختلط في أوراقها من حق ومن أكاذيب، فإن الاقتراح الذي نقدمه -للحوار حوله- بصددها، هو الذي سبق واقترحه شيخنا محمد الغزالي، عليه رحمة الله، في الندوة التي دعت إليها نقابة المهندسين-منذ سنوات بمصر والتي حضرها معنا البابا "شنودة الثالث" وفيها اقترح الشيخ الغزالي أن يعطى كل أهل دين مساحة من الأرض لبناء دور عبادتم عليها، مساوية لنسبتهم العددية إلى السكان. فهذا هو المعيار العادل، الذي يخرج هذه القضية الحساسة والحيوية من غلو الغلاة، كل الغلاة؛ غلو الذين يضيقون ببناء الكنائس، وغلو الذين يريدون لبناء الكنائس أن يكون مظهرا من مظاهر الاستقواء والتغيير لهوية المجتمع، لحساب الهوية المستوردة، التي لا علاقة لها بهويتنا المشتركة.

وإذا كان من غير المتصور أن تفرض الأقلية الدينية على الأغلبية منهاجها ومذهبها في "الدولة" كأن يسعى المسلمون، في فرنسا مثلا، بملايينهم الخمسة، إلى فرض "الدولة الإسلامية وشريعتها" على الأغلبية العلمانية للشعب الفرنسي، أو أن يمثلوا "فيتو" على التوجه العلماني للأغلبية؛ وكذلك الحال مع مائتي مليون مسلم في الهند، لأن "هوية الدولة" بالمنطق الديمقراطي هي خيار الأغلبية، فإن هذه "الدولة" التي تكون علمانية مع الأغلبية العلمانية، وإسلامية مع الأغلبية الإسلامية، مطالبة بأن لا تجور هويتها -علمانية كانت أو إسلامية- على الحق الإلهي والأقدس للأقليات في حرية الاعتقاد الديني وإقامة شعائر وفرائض الدين. فالأقليات الإسلامية، في البلاد العلمانية، مطالبة باحترام القانون الوضعي، بشرط أن يراعي هذا القانون الوضعي، حريتها في الاعتقاد الإسلامي وإقامة الفرائض الإسلامية، ومراعاة الحلال والحرام الديني في أحوالها الشخصية وحياتا الأسرية، وعدم التجريح لمقدساةًا. والأقليات غير المسلمة، في المجتمعات ذات الأغلبيات المسلمة، مطالبة باحترام قوانين الشريعة الإسلامية وفقهها، خصوصا وأن هذه القوانين مرجعيتها منظومة القيم الإيمانية المشتركة، والجانب المدني والقانوني الإسلامي، الذي لا بديل له ولا نقيض في النصرانية، وإنما هو بديل ونقيض للقانون الغربي العلماني، الذي جاءنا في ركاب الغزاة والمستعمرين. فالقانون الإسلامي هو قانون "وطني وقومي" بالنسبة لغير المسلمين، مع ضرورة مراعاة ألا يتعارض بند من بنود هذا القانون مع نص ديني جليّ جاء به الدين لغير المسلمين. 
بهذه القضايا، الأكثر حساسية، والأكثر عرضة للاستغلال، يجب أن يبدأ الحوار بين الحكماء. وإذا كانت أوراق الأقليات قد تحولت -على يد الهيمنة الغربية- من "نعمة التنوع في إطار الوحدة" إلى "نقمة تشرذم وتفتيت"، فإن العقلاء والحكماء، من مختلف الفرقاء، يجب عليهم إنقاذ الأديان من هذا الاستغلال الاستعماري، وإنقاذ الأقليات من هذا الذي تصنعه الغواية والخيانة بأقلية قليلة، أرادت وتريد تعميم جريمتها على الأغلبيات الساحقة من أبناء الأقليات.

إن التعصب رذيلة، بصرف النظر عن دين المتعصبين. أما السقوط في شباك الغواية الاستعمارية فهو الخيانة للوطن، وللدين معا. ولنتذكر -مرة أخرى- الخيار الصهيوني للأقليات كما جاء في مقررات "ندوة التسعينيات" والذي قالوا فيها: "إن هذه الأقليات هي شريكة لإسرائيل في المصير، وفي الوقوف ضد الإسلام والقومية العربية." أعاذ الله أمتنا من شرور الغواية، وحرسها من تحديات الخيانة، ووفقنا جميعا -أقليات وأغلبيات- إلى ما يرسخ وحدة أمتنا، ويعيد لها أسباب النهوض، لتأخذ مكاغا ومكانتها الجديرة بدورها التاريخي، الذي تعلمت منه الكثير من الأمم والحضارات. 